\title{
1924-2009 Tarihleri Arasında Atatürkçülük ve Türk Kültürrü Konularının Sosyoloji Dersindeki Yeri
}

\author{
Sevda Koç Akran ${ }^{1}$
}

Öz

Anahtar Sözcükler

Bu çalışmanın temel amacı, 1924 yılından 2009 yılına kadar lise sosyoloji dersinde yer alan, Atatürkçülük ve Türk Kültürü konularını belirlemektir. Araştırmada nitel araştırma yöntemlerinden biri olan doküman incelemesi kullanılmıştır. Araştırma sonucunda;1924 sosyoloji öğretim programında Atatürkçülük ve Türk Kültürü konularının ele alınmadığı, 1935, 1957 programlarında ise, Atatürkçülük ve Türk Kültürü konularına yer verildiği görülmüştür. Araştırmada elde edilen diğer sonuçlar ise; 1976 programında Atatürkçülük konusuna dolaylı ve doğrudan hiç bir gönderme yapılmadığı, buna karşın, 1986 ve 1995 programlarında Atatürkçülük ve Türk Kültürü konularının derslerde yoğun bir şekilde ele alındığı, 2009 programında ise, Atatürkçülük ve Türk Kültürü konularının yer aldığg ünitelerin, 1995 programındaki Atatürkçülük ve Türk Kültürü ünitelerine göre, oranlarında azalma görüldüğü sonucuna ulaşıııııștır.

\section{Sosyoloji Sosyoloji dersi Öğretim programları \\ Atatürkçülük \\ Türk kültürü \\ Makale Hakkında \\ Gönderim Tarihi \\ 28 Eylül 2018 \\ Kabul Tarihi \\ 14 Mart 2019 \\ Makale Türì \\ Araştırma Makalesi}

DOI: $10.12984 /$ egeefd.465049

\section{The Place of Topics of Kemalism and Turkish Culture in Sociology Subject Between 1924 - 2009}

\section{Abstract}

The main aim of this research is to determine the transfer of Kemalism and Turkish Culture topics to new generations in high school sociology lessons from 1924 to 2009. A document analysis, one of the qualitative research methods, was used in the research. As a result of the research, it was seen that the topics of Kemalism and Turkish culture were not taken into consideration in the 1924 in the sociology teaching program, and that the topics of Kemalism and Turkish culture were included in 1935 and 1957 teaching program. With regard to other findings in the research, there were no indirect or direct references to Kemalism in the 1976 program; despite that the topics of Kemalism and Turkish culture in the 1986 and 1995 programs were intensively studied in the subjects. It has been reached that the rate of the units in which Kemalism and Turkish culture topics take place decreased in 2009 program compared to Kemalism and Turkish culture units in 1995.
Keywords

Sociology Sociology lesson Teaching programs Kemalism

Turkish culture

Article Info

Received

September 28, 2018

Accepted

March 14, 2019

Article Type

Research Paper

Atıf: Koç Akran, S. (2019). 1924-2009 tarihleri arasında Atatürkçülük ve Türk kültürü konularının Sosyoloji dersindeki yeri. Ege Eğitim Dergisi, 20(1), 223-243. doi: 10.12984/egeefd.465049

\footnotetext{
1 (D) Siirt Üniversitesi, Eğitim Fakültesi, Eğitim Bilimleri Bölümü, Türkiye, sevdakc@ gmail.com
} 


\section{Extended Abstract}

\section{Introduction}

Starting from 1924, there have been some changes in our society and human development system until 2009. Especially after 1924, rapid and radical innovations have been seen in the sociology curriculum. With these innovations, in the sociology curriculum; it is intended for new generations' focusing on social institutions and events, questioning the causes of events and to know that there can be no single cause of any event. For this purpose, it is aimed to raise creative, problem-solving individuals who are dependent on their family, nation, homeland and Atatürk's principles.

\section{Method}

This research examined the transfer of Kemalism and Turkish Culture topics to new generations in high school sociology lessons from 1924 to 2009. A document analysis was used in this qualitative research. The method of document analysis is one of the methods widely used in social sciences in recent years. History, sociology and anthropology are at the top of these fields. Besides, document analysis method has been used in educational sciences. Documents can be used with other research methods, or they can singly create a complete set of data for a single study.

\section{Findings}

The sociology program prepared in 1924 French education program was prepared as an example of Louis High School Program, which was a French education program. Durkheim thought system is adopted in the program. Because Ziya Gokalp gave sociology as a lesson for the first time in education. The most important feature of the 1935 sociology course teaching program is changing the title of the course to sociology. The difference between this program and the 1924 program is to examine the subjects of Kemalism and Turkish Culture one by one and in detail. With regard to 1957 program, content was highlighted mostly among objective, content, method, which are technical elements. In terms of 1976 sociology program objectives, principles, contents, and methods, it was abolished for two years in practice because it could not respond to the conditions of the day and language was not appropriate to the student level. The 1986 program dealt with the subjects of Kemalism and Turkish Culture topics intensively. For this reason, the program was rearranged in terms of purpose, content, method and application principles. In accordance with these regulations, Elements of Turkish Culture was added to the content. In Elements of Turkish Culture, topics such as family, family in Turks, family sanctity, solidarity among family members, etc. was especially mentioned. One of these units is the Social Structure unit. With regard to 1995 Sociology Program, in the content of the program, it was seen that the subjects of Kemalism and Turkish Culture were included in Social Structure, Culture and Social Institutions and Social Change Units. When we look at the share of these units in the program, Social Structure comprises $35 \%$ (Atatürk's understanding of nationality, Atatürk's understanding of nationalism, Atatürk's understanding of populism, National unity), Culture and Social Institutions comprises $35 \%$ (Atatürk's views on culture, The place of Turkish women in Kemalist thought, The concept of laicism in Kemalist thought, Freedom of religion and conscience, The concept of secularism in the constitution, Atatürk's views on economic systems, Humanity, rights and responsibility in Kemalist thought, The importance of Atatürkism, the integrity quality of Kemalism, the difference of Kemalism from foreign ideologies), Social Change comprises $15 \%$ (Social solidarity in Kemalist thought, radical changes with Atatürk reforms) (Tebliğler Dergisi, 1995, p. 759; Yazar, 2001, p. 23). Thus, the 1995 program is very similar to the 1986 program but there are some differences between them. One of these differences is the unit names and the other is the ratio of the units within the program. That is to say, the rate devoted to Kemalism and Turkish Culture in 1986 was $60 \%$ and in 1995 it was $85 \%$. Although the program of the 2009 program has some common goals and common contents with 1995 program, there are differences in the functioning of the subjects. When we look at these differences, there are four units in the 1995 program. When we look at the 2009 program, we see that there are six units different from the 1995 program. According to the 2009 program (p.18), these units are Introduction to Sociology (8\%), Individual and Society (14\%), Social Structure (10\%), Social Change and Development (17 \%), Society and Culture (17\%) and Social Institutions (34 \%). In the 1995 program, from the units dealing with the topics of Kemalism and Turkish Culture, It is concluded that the ratio of Social Structure unit within the program has been reduced in 2009 program. 


\section{Discussion and Conclusion}

The subjects of Kemalism and Turkish Culture were handled in different ways between 1924 and 2009, and these differences were reflected in the programs of the day. Considering these reflections, due to the fact that Atatürk Principles and Revolutions did not enter into force during this period in 1924 program, it was seen that Atatürk Principles and Reforms did not take place in this period. The most important feature of the 1935 sociology course is to change the name of the course to sociology. The difference of the program from 1924 program is examining the topics of Kemalism and Turkish Culture individually and to examine them in detail. Another feature of the program is that it questions some current social problems. When the 1957 program is considered, the most content among the purpose, content, method-technical elements has been highlighted. In the program, issues such as the principle of nationalism, the principle of secularism, the rights of women, etc., are also mentioned in the context of Kemalism and Turkish Culture. At the same time, political developments taking place in the conditions of the day apart from the subject of Kemalism and Turkish Culture were included in the program. When the objectives of the 1976 sociology program were examined, it was removed two years later due to the fact that its content and methods did not respond to the conditions of the day and the language was not suitable for the student level. During this period, no direct and indirect information on the subjects of Kemalism was included in the program and the textbook. On the other hand, it has been concluded that the issue of Turkish Culture has been given a wide scope. The program of 1986 has focused on the subjects of Kemalism and Turkish Culture intensively. For this reason; purpose, content, method and application principles are rearranged. In line with these regulations, Elements of Turkish Culture has been added to the content. Within the Elements of Turkish Culture, especially the family, the family in the Turks, the family's holiness, solidarity among the family members are mentioned. In 1995, it was seen that the subjects of Kemalism and Turkish Culture were in Social Structure, Culture and Social Institutions and Social Change Units. 


\section{Giriş}

Bireyin yaşadığı topluma uyumunu kolaylaştıran, bireyde istendik davranışları oluşturan eğitim (Çağlayan, 2004), toplumların kalkınması, refah düzeyine ulaşması, nitelikli bireylerin yetiştirilmesi sürecine katkı sağlayan önemli bir araçtır. Eğitimle, toplumdaki farklı kültürler, inançlar, değerler, bilgi ve beceriler etkileşim halinde olmaktadır (Uçan, 1989). Böyle bir etkileşimi eğitim, başta aile ortamında gerçekleştirmektedir. Daha sonraki süreçte bu görevi okullar üstlenmektedir. Aile eğitiminden sonra gelen ve bireyin yaşam boyu öğrenmesi yolunda olmazsa olmaz olarak görülen okul, bireyin gelecek hedeflerini gerçekleştirmede rehber olan, bireye sosyal mirası aşılayan, programlardaki amaçları bireye aktaran/kazandıran bir örgüttür (Başaran, 2006; Bursalıoğlu, 1992). Okul bu hedefini gerçekleştirirken, birçok araçtan yararlanmıştır. Bunlardan biri uygulamaya koyduğu eğitim/öğretim programlarıdır. Programlar, bireye kazandırılmaya çalışılan istendik davranışların öğrenme-öğretme sürecinde planlı-programlı aktarılmasını sağlayan, okul ve okul dışında tasarlanıp oluşturulan faaliyetler bütünüdür (Demirel, 2010; Erden, 1998; Güleryüz, 2000; Karakaya, 2004). Bu bütünlük ders kazanımlarına, ders temalarına, eğitim durumlarına, ölçme ve değerlendirme kriterlerine, yetiştirmek istediği öğrenci profiline göre farklılık göstermektedir. Böyle bir farklılık, derslerin/öğretim programlarının uygulanma koşullarını etkilemektedir. Mesela insan davranışlarını araştıran, toplumsal olayları sorgulayan, toplumda yaşanan problemlere çözüm üretecek bireyler yetiştirmeyi amaçlayan sosyoloji, Cumhuriyetten günümüze yaşanan siyasi ve sosyal olaylardan, dünyadaki teknolojik gelişmelerden etkilenen derslerden biridir. Başka bir deyişle sosyoloji, sanayi devriminin ortaya çıkardığı bunalımlara çare olmak üzere, üretilmiş zihni bir çalışmadır.

Sosyoloji bilimini kuran ve kavramlaştıran Fransız pozitivist filozof Auguste Comte (1798-1857), sosyolojiyi ilk olarak sosyal fizik kavramı ile nitelendirmek istemiştir. Comte'nin sosyolojiye sosyal fizik adını vermek istemesindeki temel amaç, kuracağı bu yeni bilimin fizik gibi deney ve gözlem yapan pozitif bir bilim olmasıdır. Comte'nin düşünceleri bütünüyle gerçekleşmemiştir (Arslanoğlu, 2000). Çünkü Hollandalı istatistikçi Adolph Quetelete sosyal fizik kavramını kullandığı için, kavram kargaşası yaşanmaması için, Comte sosyal fizik yerine, sosyoloji kavramını kullanmıştır (Aslantürk ve Amman 1992; Zabun, 2002).

Auguste Comte'den sonra, gerek Fransa'da gerekse Almanya ve İngiltere başta olmak üzere, diğer batı ülkelerinde farklı sosyoloji ekolleri ve anlayışları ortaya çıkmıştır. Marx'tan, Hegel'e, Durkheim'den T. Parsons'a, M. Weber'den Bottomore'a varıncaya kadar çok ünlü sosyologlar yetişmiştir. Çünkü bütün Avrupa toplumları, sanayi devriminin toplum yapılarını değiştirmesi nedeniyle, daha sağlıklı bir ortamda yaşayabilmek için, çareler aramaya başlamışlardır. Sosyolojinin Avrupa'da ortaya çıkışını ve temel gerekçelerini Cemil Meriç şöyle anlatır: "Sosyoloji bir buhranın çocuğu. Çağdaş batı düşüncesi üç başlı: ekonomi politik, sosyalizm, sosyoloji. Burjuvazi yaptıklarını anlamak, yapacaklarını programa bağlamak istiyor. Sosyoloji bir bakıma mistifikasyon, bir bakıma jüstifikasyon. Nihayet mevcut düzenin müdafaasını üzerine alan yeni bir teoloji” (Meriç, 2002, s. 177). Başka bir deyişle, 18. yüzyılın sonları ile 19. yüzyılın başlarında, Avrupa ve Amerika'da sosyoloji ekollerinin ortaya çıkışının sebepleri, sosyologların içinde bulundukları toplumları daha iyi anlamak, kurumlar arası ilişkileri çözmek ve geleceği daha iyi planlamaktır. Bu süreçte, Osmanlı devletinde gerçek anlamda bir sanayi devrimi yaşanmasa da, sosyoloji biliminin yeni bir toplum yaratma, yeni toplumu meşrulaştırma misyonu, Osmanlı aydınlarını da adeta büyülemiştir. Dolayısıyla, 18. yüzyılın ortalarından itibaren, Osmanlı aydınları arasında sosyolojiyle ilgilenenler, sosyolojinin imkânlarına yer verenler ortaya çıkmıştır. Başta Ahmet Cevdet Paşa olmak üzere, Tanzimat ve I. Meşrutiyet dönemlerinde Namık Kemal, Ziya Paşa, Ali Suavi, Ahmet Mithat Efendi, Beşir Fuad, Abdullah Cevdet, Ahmed Rıza ve II. Meşrutiyet devrine gelindiğinde de Prens Sabahattin, Ziya Gökalp, Bedi Nuri, Ahmet Şuayp, Satı Bey, Mehmet İzzet, Necmettin Sadak, İsmail Hakkı Baltacıoğlu ve daha pek çok aydın sosyolojik kavram ve ilkeleri kullanmaya başlamışlardır (Ergun, 1979). Bunlar içerisinde, Türkiye'de sosyolojiyi ilk defa Beşir Fuat kullanmıştır. Ardından sosyolojiyi okullarda ilk kez 1911'de Ziya Gökalp İttihat ve Terakki Lisesinde içtimaiyat adı altında okutmaya başlamıştır. Gökalp tarafından kullanılan içtimaiyat, Fransa'daki sociology kavramının karşılığı olarak cemea kökünden türetilmiş ve Türkçeye kazandırılmış bir kelimedir.

Ziya Gökalp ile okullarda okutulmaya başlanan içtimaiyata (sosyoloji), Osmanlı ve erken Cumhuriyet aydınları tarafından çok önem verilmiş, üzerinde çok durulmuştur. Bunun bazı temel sebepleri vardır. Bu sebeplerin başında, Osmanlı devletinin içinde bulunduğu sosyal, siyasî, kültürel ve ekonomik bunalım gelmektedir. Öyle ki, içinde bulunulan bu sıkıntılı durumdan kurtulabilmek için, devlet adamları ve aydınlar düşündükleri her kurtuluş reçetesine başvurmuşlardır. Son dönem Osmanlı aydınları tıpkı sosyolojinin Avrupa'da oynadığı rolü örnek alarak, işe başlamak istemişlerdir. Onlara göre; "Bir cemiyet dâhilindeki müesseseleri sslah ve tedavi etmek için bu müesseselerin mahiyetini, ne gibi kanunlara tabi bulunduğunu bilmek gerekir." (İçtimaiyat Mecmuası, 1917, s. 2). Bunun için pek çok aydın Türkiye Nasıl Kurtarılabilir? benzeri eserler ve çözüm önerileri sunmuşlardır (Güngör, 1982). Bu öneriler içerisinde, son dönem Osmanlı, erken dönem Cumhuriyet aydınlarının öncülerinden Ziya Paşa her şeyiyle farklı ve yeni bir nesil yaratmak isteğiyle, işe çocuktan başlamak gerektiğini düşünmüsştür (Meriç, 1974). Bu düşünceyi hayata geçirmek amacıyla, J. J. Rousseau'nun modern pedagojinin başlangıcı 
sayılan eseri Emile'i tercüme etmeye başlamış, ancak bitirememiştir. Bu anlayış ve gayret Cumhuriyet dönemine kadar devam etmiştir. Özellikle II. Meşrutiyet devrinde, İttihat ve Terakki aydınları yeni bir toplum ve devlet yaratmak emeliyle, bu gayeye ulaşabilmenin yollarını aramışlardır. Bu arayışta onlara en büyük yol göstericiler, Ziya Gökalp ve Yusuf Akçura olmuştur. Devlet programlarından eğitim ve öğretime, ticaret ve sanayiden sanat ve estetiğe varıncaya kadar, yeni programlar hazırlanmış ve tatbik edilmeye çalışılmıştır. Bütün bunların halk tarafindan kabul görebilmesi için, eğitime çok ayrı ve derin bir önem verilmiştir. Eğitime verilen önemin yansıması olarak, programlara bir takım dersler konulmuștur. Bu derslerden biri içtimaiyattır. Cumhuriyetten günümüze düşünürler ve bilim adamları tarafından önemli bir alan olarak görülen İçtimaiyat (sosyoloji), liselerde 1924'ten itibaren bir ders olarak okutulmaya başlanmıştır (Başgöz, 1995; Yücel, 1938). Sosyolojinin İçtimaiyat adıyla, 1924 orta öğretim programlarına alınmasının gerekçesi, Lise müfredat programı Esbab-1 Mucibe Layıhasında şöyle ifade edilmiştir:

"Felsefe derslerinde eski programla bu program arasındaki esaslı fark içtimaiyatın eklenmesi ve on birinci sınıfın edebiyat şubesinde felsefi konular çerçevesinde çeşitli meselelerin öğretilmesine gerek görülmesidir. Programı düzenleyen kurul, ikinci devre, öğrencisinin toplumsal sorunlar üzerinde düşünmesini, onların birey üzerindeki etkilerinin bilinmesini ve evrim hakkında fikir edinilmesini gerekli görmüştür. Daha önce dersler ayrı ayrı okutularak hukuksal ve ekonomik sorunların birbirleriyle ilişkisi gösterilmezken şimdi bunların birer toplumsal kurum olmaları nedeniyle birbirlerine olan etkileri özellikle gelişme evreleri öğrenciye öğretilecek ve toplumun gelişimiyle birlikte bunların da değişim hakkında yeterli fikir ve bilgi verilecektir.” (Tan, 1987, s. 168).

Lise müfredat programı Esbab-1 Mucibe Layıhasında görüldüğü üzere, 1924 yılında lise müfredat programlarında, İçtimaiyatın yer alması ve önemi üzerinde durulmasının nedenleri arasında, Cumhuriyet'in kurulduğu ilk yıllarda, sosyal olaylar hakkında gençlerin bilgilendirilmesi yer almaktadır. Bu amaçla, İçtimaiyat dersinin hedefleri arasında öğrencinin toplumsal sorunlar üzerinde düşünmesi ibaresi yer almıştır (Zabun, 2002). $\mathrm{Bu}$ düşünceyle hareket eden Bakanlık, ders kitaplarında Cumhuriyetin esaslarını temele alan görüşlere yer vermiştir. Böylelikle dönemin Eğitim Bakanı olan Vasıf Bey ve 43 kişilik program heyeti ilk, orta ve lise programlarında bir takım değişiklikler yapmışlardır. Yapılan değiş̧ikliklerden biri, lise programlarına İç̧imaiyat dersinin konulmasıdır. İçtimaiyat dersi ile ilkin önceki devrin ideolojisine bağlı olan görüşler kitaplardan ayıklanmış ve yerine Cumhuriyetin esasları konmuştur (Çimen, 1997). 1924 yılındaki programda yer alan İçtimaiyat dersinde yapılan bu değişikler, 1935 yılında uygulamaya konulan programda da devam etmiştir. 1935 programının temel amaçları içerisinde; "gençleri sosyal vakıalar üzerinde düşündürmeye ve bunlar arasındaki ilgileri araştırmaya alıştırmak ve gençleri Türk devriminin amaç bildiği ideallerin fikri temellerini kavrayacak hale getirmek ve böylece Türk toplumunun gelişmesine yarayacak işler yapacak yurttaşlar yetiştirmek" ibaresi yer almaktadır. Yani 1935 programı ile yeni nesillerden sadece toplumsal olgular üzerinde fikir yürütmesi değil, aynı zamanda toplumsal olgular üzerinde tutum takınması konusunda davranışlar sergilemesi beklenilmiştir (Yazar, 2001). Mesela, 1935 programında; sendikacılık, kooperatifçilik, sanayileşme, demiryolu, bankacılık, devletçilik, aile hukuku, kadın-erkek eşitliği, dil, kültür, ideal birliği, sosyal yardım, ulusal egemenlik, Cumhuriyetçilik ilkeleri gibi bir takım güncel konular ele alınarak, gençlerin bu konular üzerinde düşünmeleri ve bu konularda karşılaşılan problemlere çözüm yolları üretmeleri amaçlanmıştır (Beydoğan, 1988). Bu amaçlar doğrultusunda ele alınan konular, 1957 yılında uygulanan programda da önemini korumuştur.

Günün koşulları içerisinde yaşanan siyasi gelişmelerin programlara yansıması, sadece 1957 programında değil, 1976 ve daha sonraki programlarda da kendisini göstermiştir. Mesela 1976 programında, Atatürkçülük konusuna dolaylı ve dolaysız hiçbir gönderme yapılmazken, Türk Kültürü konusuna geniş yer verilmiştir. Türk Kültürünün yeni nesiller tarafından özümsenmesi için de, programa "Türk Milletinin sosyal ve kültürel mirasını kavramalarında imkân ve zemin hazırlamaktır." şeklinde amaçlar eklenmiştir. Bunun yanı sıra, sosyoloji öğretmenlerine, "Milli birlik ve beraberliğin dil, kültür ve ülkü birliğiyle sıkı ilişkisine zaman zaman temas firsatları aramaları, sosyal olayları tarihi akışına da dikkat çekerek öğrencilerin diğer derslerden elde ettiği bilgilerden faydalanarak, sosyolojinin verileriyle öğrencilerin bilgilerinin genişletilmesine gerektiği ölçüde yer vermeleri” gibi sorumluluklar yüklenmiştir (Zabun, 2002, s. 26-27). Türk Kültürü konusunda öğretmene yüklenen bu sorumluluklar, 1980 ve sonrasında da devam etmiştir. Fakat 1980 yllında öğretmene, Türk Kültürü konusunun yanında, Atatürkçülük konusunun da genç nesillere benimsetilmesi görevi verilmiştir. Öğretmene verilen bu görev, 1986 programında da devam etmiştir. Öğretmenden programdaki sosyal konuların, Atatürkçü düşünce konusu ile kaynaştırılarak, aktarılması istenilmiştir. 1980 yılından sonra yaşanan bu gelişmeler, 1995 sosyoloji programının da temellerini oluşturmuş, başka bir deyişle, 1986 yılında programda yer alan ve önemli konulardan biri olan Atatürkçülük ve Türk Kültürü konuları, 1995 programında da yerini korumuştur.

Kısaca belirtmek gerekirse, 1924 yılından başlanarak, 2009 yılına kadar gerek toplum, gerekse insan yetiştirme sistemimizde bir takım değişikliklerin yaşandığı söylenebilir. Özellikle 1924 yılından sonra sosyoloji öğretim programında, hızlı ve köklü yenilikler görülmüştür. Yapılan bu yeniliklerle sosyoloji öğretim programında; yeni 
nesillerin; toplumsal kurumlara ve olaylara odaklanması, olayların sebeplerini sorgulaması, hiçbir olayın tek nedeninin olamayacağını bilmesi, ailesine, milletine, vatanına, Atatürk ilkelerine bağlı yaratıcı, problem çözücü bireyler olarak yetiştirilmesi amaçlanmıştır. Böyle bir amaç günümüze kadarki programlarda ifade edilmiştir. Özellikle sosyoloji dersinde Atatürkçülük ve Türk Kültürü konularıyla ilgili yapılan değişiklikler konusunda literatürde çok fazla araştırma bulunmamaktadır. Bu yönüyle çalışmanın ilgili alanda çalışanlar için bilgilendirici ve kaynak bir çalışma olacağı düşünülmüş ve araştırmanın problem cümlesi 1924-2009 tarihleri arasında Atatürkçülük ve Türk Kültürü konularının Sosyoloji dersindeki yeri olarak belirlenmiştir. Araştırmanın problem cümlesinden hareketle aşağıdaki sorulara yanıt aranmıştır:

1. 1924 ve 1935 sosyoloji dersinde Atatürkçülük ve Türk Kültürü konuları nelerdir?

2. 1957 ve 1976 sosyoloji dersinde Atatürkçülük ve Türk Kültürü konuları nelerdir?

3. 1986 sosyoloji dersinde Atatürkçülük ve Türk Kültürü konuları nelerdir?

4. 1995 sosyoloji dersinde Atatürkçülük ve Türk Kültürü konuları nelerdir?

5. 2009 sosyoloji dersinde Atatürkçülük ve Türk Kültürü konuları nelerdir?

\section{Yöntem}

\section{Araştırmanın Deseni}

1924-2009 yılları arasında Atatürkçülük ve Türk Kültürü konularının sosyoloji dersindeki yerini belirlemek amacıyla, yapılan bu çalışmada, nitel araştırma yöntemlerinden biri olan doküman incelemesi yöntemi kullanılmıştır. Doküman incelemesi Tarih, sosyoloji ve antropoloji, eğitim alanlarında olduğu gibi, son yıllarda sosyal bilimler alanında yaygın olarak kullanılmaya başlanmıștır. Bir araştırmada kullanılacak dokümanlar, nitel ve nicel çalışmalarda kullanılabileceği gibi, sadece tek başlarına bir araştırmanın tüm veri setini de oluşturabilmektedir (Yıldırım ve Şimşek, 2003).

\section{Veri Toplama ve Analiz Süreci}

Araştırmada doküman incelemesi yöntemi kullanılırken belirli aşamalar dikkate alınmıștır. Bunlar; dokümanlara ulaşma, orijinalliğin kontrol edilmesi, dokümanların anlaşılması, verinin analiz edilmesi ve verinin kullanılmasıdır. Araştırmada ilk olarak, araştırmanın problem cümlesinden hareket edilerek araştırma kapsamına alınacak dokümanların listesi oluşturulmuştur. Doküman listesinin oluşturulmasında, amaçlı örnekleme yöntemlerinden kolay ulaşılabilir durum örneklemesine başvurulmuştur. Yıldırım ve Şimşek’e (2003) göre bu örnekleme yöntemi, nitel araştırmalarda yaygın olarak kullanılmakta, araştırmaya hız ve pratiklik kazandırmaktadır. İkinci olarak, ulaşılan dokümanların birincil ve ikincil kaynak olup olmadığı tespit edilmiştir. Burada amaç, uzmanlar tarafından hazırlanan kaynaklar arasında tutarlığı belirlemek, araştırmanın güvenirliğini sağlamak ve dokümanları anlaşılır kılmaktadır. Üçüncü olarak elde edilen dokümanlar araştırmanın alt problemleri dikkate alınarak tek tek ele alınmıştır. Dokümanlar ele alınırken, basım yılı, ele alınan konu ve ulaşılan dokümanlar şeklinde kategorileştirilmiştir.

Tablo 1'de görüldügü üzere, 1924 yılında Atatürkçülük ve Türk Kültürü konuları, 1976 yılında ise Atatürkçülük konusu sosyoloji dersinin amaçları arasında yer almamaktadır. 1935, 1957, 1986, 1995 ve 2009 yılları arasında her iki konu dersin amaçları arasında bulunmaktadır. Ayrıca Tablo 1'de sosyoloji ders programının uygulandığı her yıl için araştırma kapsamına alınan dokümanlara ait bilgiler yer almaktadır.

Tablo 1

Araştırma Kapsamına Alınan Dokümanların Yıl, Konu ve Kaynak Dağılımları

\begin{tabular}{|c|c|c|c|}
\hline \multirow{2}{*}{ Y1l } & \multicolumn{2}{|c|}{ Konu } & \multirow{2}{*}{ Kaynak } \\
\hline & Atatürkçülük & Türk Kültürü & \\
\hline 1924 & - & - & $\begin{array}{l}\text { T.C. Kültür Bakanlığı (1938). Lise Programı. İstanbul.: Devlet } \\
\text { Basımevi 1340/1924 Tarihli orta Mektep ve Lise programlarına } \\
\text { Zeyl:57-59 }\end{array}$ \\
\hline \multirow[t]{2}{*}{1935} & \multirow[t]{2}{*}{$\sqrt{ }$} & \multirow[t]{2}{*}{$\sqrt{ }$} & $\begin{array}{l}\text { Tebliğler Dergisi, Cilt 4, Sayı 138, Y11 } 1941 . \\
\text { Tebliğler Dergisi, Cilt 10, Sayı 450, Y11 } 1947 . \\
\text { Tebliğler Dergisi, Cilt, 17, Say1, 816, Y11 } 1954 . \\
\text { Sadak, N. (1939). Sosyoloji. İstanbul: Maarif Matbaası. }\end{array}$ \\
\hline & & & $\begin{array}{l}\text { MEB, (1952). Lise Müfredat Programı. Ankara: Milli Eğitim } \\
\text { Basımevi. }\end{array}$ \\
\hline
\end{tabular}


Tablo 1 -devam

\begin{tabular}{|c|c|c|c|}
\hline \multirow{2}{*}{ Y1l } & \multicolumn{2}{|c|}{ Konu } & \multirow{2}{*}{ Kaynak } \\
\hline & Atatürkçülük & Türk Kültürü & \\
\hline 1957 & $\sqrt{ }$ & $\sqrt{ }$ & $\begin{array}{l}\text { T.C. Maarif Vekâleti (1956). Lise Programı. Ankara: Maarif } \\
\text { Basımevi. } \\
\text { Tebliğler Dergisi, Cilt, 20, Say1, 976, Y11 1957. } \\
\text { Tebliğler Dergisi, Cilt, 22, Say1, 1086, Y11 1959. } \\
\text { Tebliğler Dergisi, Cilt 23, Say1 1117, Y11 1960. } \\
\text { Tebliğler Dergisi, Cilt 23, Say1 1119, Y11 1960. } \\
\text { T.C. Maarif Vekâleti (1960). Lise Programı. Ankara: Maarif } \\
\text { Basımevi. }\end{array}$ \\
\hline 1976 & - & $\sqrt{ }$ & $\begin{array}{l}\text { MEB (1970). Lise Müfredat Programı. Ankara: Milli Eğitim } \\
\text { Basımevi. } \\
\text { MEB (1973). Lise Müfredat Programı. Ankara: Milli Eğitim } \\
\text { Basımevi. } \\
\text { Tebliğler Dergisi, Cilt 43, Sayı, 2062, Y11, 1980. } \\
\text { Kurtkan, A.(1980). Sosyoloji. İstanbul: Milli Eğitim Basımevi } \\
\text { Kaplan, İ. (2002). Türkiye'de Milli Eğitim İdeolojisi. İstanbul: } \\
\text { İletişi Yayınları. }\end{array}$ \\
\hline 1986 & $\sqrt{ }$ & $\sqrt{ }$ & Tebliğler Dergisi, Cilt 41, Sayı, 2104, Y11, 1981. \\
\hline 1995 & $\sqrt{ }$ & $\sqrt{ }$ & $\begin{array}{l}\text { Merter, F. ve Yıldız, H.(2010). "Cumhuriyetten Günümüze Lise } \\
\text { Programlarının Atatürk İlke ve İnk1lâplarını Genç Nesillere } \\
\text { Benimsetmesi Bakımından Değerlendirilmesi." Mehmet Akif } \\
\text { Ersoy Üniversitesi Eğitim Fakültesi Dergisi, Yıl 10, Sayı 20:.1-27. }\end{array}$ \\
\hline 2009 & $\sqrt{ }$ & $\sqrt{ }$ & $\begin{array}{l}\text { MEB (2009). Ortaöğretim Sosyoloji Dersi Öğretim Programı. } \\
\text { Ankara: Milli Eğitim Bakanlığı Yayınları. }\end{array}$ \\
\hline
\end{tabular}

\section{Bulgular}

Burada alt problemlere göre, araştırmadan elde edilen bulgular sırasıyla verilip yorumları yapılmıştır.

\section{4 ve 1935 Sosyoloji Dersinde Atatürkçülük ve Türk Kültürüi Konularına İlişkin Bulgular}

1924 ve 1935 sosyoloji dersinde Atatürkçülük ve Türk Kültürü konularına ilişkin bulgular Tablo 2'de yer almaktadır.

Tablo 2

1924 ve 1935 Sosyoloji Dersinde Atatürkçülük ve Türk Kültürü Konuları*

\begin{tabular}{|c|c|c|c|c|}
\hline Y1l & Konu & Amaç & İçerik (Muhteva) & Öğretim Yöntemi \\
\hline 1924 & $\begin{array}{l}\text { Atatürkçülük } \\
\text { Türk Kültürü }\end{array}$ & - & - & - \\
\hline \multirow{5}{*}{1935} & \multirow{4}{*}{ Atatürkçülük } & \multirow{4}{*}{$\begin{array}{l}\text { Gençleri Türk } \\
\text { devriminin amaç } \\
\text { bildiği ideallerden } \\
\text { fikri temellerini } \\
\text { kavrayacak hale } \\
\text { getirmek. }\end{array}$} & $\begin{array}{l}\text { Son Asır Milletlerin Teşekkülü } \\
\text { Türkiye'de milliyet fikrinin doğuşu ve } \\
\text { Türk inkılabının milliyetçilik fikri }\end{array}$ & \multirow{4}{*}{-} \\
\hline & & & $\begin{array}{l}\text { Devlet } \\
\text { Türk devriminde Halkçılık }\end{array}$ & \\
\hline & & & $\begin{array}{l}\text { Devletin Gördüğ̈̈ İsler } \\
\text { Devletçilik } \\
\text { Hükumet } \\
\text { Türkiye Cumhuriyeti }\end{array}$ & \\
\hline & & & $\begin{array}{l}\text { Din } \\
\text { Dinin ferdi vicdanlara geçmesi: Laiklik }\end{array}$ & \\
\hline & Türk Kültürü & - & $\begin{array}{l}\text { Aile ve Kadın } \\
\text { Türkiye'de aile } \\
\text { Ailenin muhtelif şekilleri }\end{array}$ & - \\
\hline
\end{tabular}


İçtimaiyat bir ders olarak ilk defa, 1924 lise programında yer almıştır. Bu programın içeriği hazırlanırken, Fransa Eğitim Bakanlı̆̆ı'nın 1920'deki programı (St. Louis Lisesi Programı) dikkate alınmıştır. Fransız eğitim sisteminden alınan program, ülkemizin eğitim düzeyi dikkate alınmadan uygulanmış; hatta liselere program Fransizca gönderilmiştir (Mengüşoğlu, 1975).

Fransa eğitim sisteminden alınan programda içtimaiyat, liselerin iki kolunda yani, Fen ve Edebiyat kollarında okutulmuştur. Liselerde Fen ve Edebiyat kollarının iki ayrı kola ayrılması ilk defa 1923 de, I. Heyet-i İlmiye toplantısında alınan bir kararla olmuştur. Çünkü Osmanlının son zamanlarında okullarda çeşitliliğin olması, beraberinde bir takım problemleri de getirmiştir. Bu problemleri en aza indirmek için, aynı düzeydeki okullar arasında bilgiyi eşitlemek amacıyla, okullarda bölümler Fen ve Edebiyat kolu olarak ayrılmış ve bu kollarda felsefe ve içtimaiyat dersleri okutulmuş̧ur (Beydoğan, 1988). Bu dersler, Fen şubelerinin ikinci sınıfinda iki saat, üçüncü sınıfında üç saat, Edebiyat şubelerinin ikinci ve üçüncü sınıflarında ise, ikişer saatten altı saate çıkartılmıştır. Yapılan bu uygulamalar, 1927'de de kısmî değiş̧ikliklerle aynen kabul edilmiş̧ir. 1927'de yapılan değişiklikte: "Fen şubesinde ayrıca ahlak felsefesi okutulması faydasız görülmüş, bu şube için içtimaiyat dersleri arasındaki ahlâkî içtimaiyat bahsi kâfi addolunmuştur. Binaenaleyh fen şubesindeki ahlak felsefesi okutulmayacağı için felsefe ve içtimaiyat saatinden biri tenzil edilerek üç saat bırakılmıştır." (1340/1924 Tarihli orta Mektep ve Lise programlarına Zeyl, s. 57-59). Yani 1927 yllındaki değişiklikte, Fen şubesinde okutulan ahlak felsefesi yerine, ahlâkî içtimaiyat okutulmuş̧ur. Lise son sınıflarında, Fen ve Edebiyat kollarında okutulan İçtimaiyat dersinin amaçları arasında; ikince devre öğrencilerin toplumsal sorunlar üzerinde düşünmesine, evrim hakkındaki bilgilere vb. yer verilmiştir (Beydoğan, 1988). Bu amaçlar doğrultusunda, İçtimaiyat dersinin muhtevası üç bölümden oluşmuştur. Bunlar; iktisat sosyolojisi, aile sosyolojisi ve siyaset sosyolojisidir (Yazar, 2001). Programın sonunda din, sanat ve toplum ilişkisine de değinilmiştir. Muhtevanın bu konulardan oluşmasının nedeni, Fransız metoduna ve Durkheim sosyolojisine bağlı kalınmasıdır (Ülken, 1966, s. 57). Buna karşın programın gerek amaçları, gerekse de muhteva (içerik), yöntem ve tekniklerinde Atatürkçülük ve Türk Kültüründen söz edilmemiş̧tir. Bunun sebebi, inkılâpların çoğunun yürürlüğe girmemesidir (Merter ve Yıldız, 2010) (Bkz: Tablo-2).

1924 lise müfredat programlarından sonra, uygulamaya konulan 1935 programına kadar belirli yıllarda ders çizelgelerinde değişiklikler olmuştur. Mesela, 1927 yllında Felsefe grubu haftada altı saattir ve bu altı saatin iki saati İçtimaiyat derslerine ayrılmıştır (Yücel, 1938). 1930 yılındaki lise, orta mektepler talimatnamesinde ise, öğretmenlerden Cumhuriyet eğitimi vermeleri için bir takım derslerin daha ön plana çıarılması istenilmiştir. Bu derslerden bazıları, Türkçe, Coğrafya, Yurt Bilgisi, Sosyoloji, Felsefe, Cumhuriyet ve Yurttaşlık Bilgisidir. 1931 yılına kadar, sosyoloji programında değişiklikler yapılmamıştır. 1934 yılına gelindiğinde ise, lise programlarında değişiklik yapıldığı belirtilse de fazla bir değişiklik fark edilmemiş̧tir (Çimen, 1997). 1935 yılına gelindiğinde ise, yeni sosyoloji programı kabul edilmiştir.

31.8.1935 tarih ve 153 sayılı kararla kabul edilen 1935 programı, Fen kolu son sınıfta üç saat, Edebiyat kollarında ise altı saat olarak okutulmuştur. 1935 programı, 1924 programından farklı özellikler taşımaktadır. Bu farklılıklardan biri, dilinin sade olması ve dersin adının Sosyoloji olarak değiştirilmesidir (Beydoğan, 1988; Cicioğlu, 1985; Tan, 1987). Programda yapılan değişiklikler, bununla sınırlı kalmamıştır. 1935 sosyoloji programının muhtevasında da bir takım değişiklikler gözlenmiş̧tir. Programın muhtevası felsefe grubu derslerinden beklenen amaçlardan yola çıkılarak hazırlanılmıştır. Dersin muhtevası içerisinde; sendikacılık, kooperatifçilik, sanayileşme, kabotaj ve demiryolu, tekelcilik, bankacılık, özel mülkiyet, devletçilik, aile hukuku, kadın-erkek eşitliği, dil, kültür, ideal birliği, sosyal yardım, ulusal egemenlik, Cumhuriyetçilik ilkeleri konuları ayrıntılı bir biçimde ele alınmıştır. Öğretmenden beklenen ise, bu ilkelerin doğruluğunu, verimini ve faydalarını vurgulamasıdır (Tan, 1987, s. 172). Öğretmene yüklenen bu sorumluluk doğrultusunda, Atatürkçülük ve Türk Kültürü konusunda, programda öğretmenin göz önünde bulunduracağı noktalar bölümünde aşağıdaki ilkelere yer verilmiştir (T.C. Kültür Bakanlı̆̆ı, 1938, s. 18-19):

Kitaptan Türkiye'de aile bahsi okutulurken öğretmen medeni kanunun aile hukukunda yaptığı devrim üzerinde çok durmalı ve eski fıkıh esasları ile arasındaki ayrılık belirtilmelidir.

Ulusal birliğin dil, kültür, ideal birliğine dayandığı gösterilecektir.

Demokrasiyi doğuran sebepler söylendikten sonra Türk Devleti'nin (Ulusal Egemenlik) idealine bağlılığı belirtilecektir.

Ulusal devletin vazifelerinin nasıl genişlediği gösterilerek devletin sosyal yardım ve ekonomik devletçilik prensibi anlatılacaktır

Hükümet şekilleri bahsinde ulusal hükümetin kurulmasına sebep olan vakalar üzerinde durulacak ve devrimin Cumhuriyet prensibi esaslı muhakemeye dayanan bir kanaat halinde anlatılacaktır.

Din meselesine türlü noktadan bakım kabil olduğu anlatıldıktan sonra sosyoloji bakımından din meselesi üzerinde durulacak, ulusal devletin laik olmasını doğuran sebepler anlatılacaktır. 
Programda, Atatürkçülük ve Türk Kültürü konusunda yapılan bu açıklamalar okullarda okutulan ders kitaplarında da yer almıştır. Bu özelliğinden dolayı, 1935 programı, 1924 programından farklı bir yapıya sahiptir. Bu farklılıklar sonucunda, 1924 programının eksiklikleri eğitimciler ve sosyologlar tarafından tartışılmıştır. Tartışmalardan biri, Hilmi Ziya Ülken tarafından, 1932 yılında Umumi İçtimaiyat kitabında dile getirilmiştir. Ülken tarafından yapılan eleştiriler sonucunda, dönemin Milli Eğitim Bakanlığı özel bir komisyon kurmuştur. Milli Eğitim Bakanı Saffet Arıkan zamanında kurulan bu komisyon, 31.08.1935 tarih ve 153 sayılı kararla Mehmet İzzet'in içtimaiyat listesinden çıkarılmasına, yerine Necmettin Sadak'ın getirilmesine karar vermiştir (Çimen, 1997). Bu karar doğrultusunda Tebliğler dergisinde (8 Eylül 1941; 8 Eylül 1947) sosyoloji ders kitaplarının Necmettin Sadak tarafından yazılması konusunda bilgilere yer verilmiştir. Sadak’ın kitaplarında üzerinde durduğu en önemli konulardan biri, Atatürkçülük ve Türk Kültürüdür. Atatürkçülük ve Türk kültürü konusundaki düşüncelerini, 1939 yılında liseler için hazırlamış olduğu ders kitabında da ayrıntılı bir şekilde ele almıştır. Liseler için hazırlamış olduğu sosyoloji kitabında, Atatürkçülük ve Türk Kültürü konusundaki düşüncelerini şu şekilde açıklamıştır:

“...Türk İnkılabının, kendine yol gösterici kaideler olarak aldığı umdelerden biri milliyetçiliktir. Bundan maksat, asrın ilerleme ve teknik hareketinde diğer ileri milletlerle birlikte yürümek, fakat milli karakter ve benliğini korumaktır: Medeniyette, Avrupa medeniyeti, kültürde Türk Kültürü...Türk Milletinin kamusal vicdanı, tehlike ve birlik zamanında kendi iradesini temsil edecek şahsiyetin, cemiyetin manevi kudretini nefsinde toplamağa muktedir olması lazımdır. Türk Milletinin kamusal vicdanı, tehlike ve birlik zamanında kendi iradesini temsil edecek bir şef üzerinde belirledi: Mustafa Kemal... Bu suretle, milli kuruluş ve kalkınma hareketini yapan Mustafa Kemal sosyolojik bir anlatılma, büyük bir milli, heyecan ve galeyan anında, halkın birleşik vicdanın doğurduğu sosyal bir semboldür. Kuvvet ve kudretin yüksekliği, şahsın temerküz eden-eskilerin 'kut' adını verdikleri - milli vicdanın kudret ve kesafetinden ileri geliyor... Türkiye Devleti, demokratik, halkçı olduğu için laiktir.” (Sadak, 1939, s. 45-61-97).

Türk Kültürü konusunda ise;

"Medeni kanundan önceki devirde, Osmanlı devrinde aile soy şeklinde pederşahi tipin karışmasından doğmuştur. Türkiye'de inkılabın aile değişmesine kadar süren bu aile tipi, dini ahkama dayanırdı. Belli başıı bir aile kanunu yoktu... Türk ailesi ancak İnkılaptan sonra, bütün şekilleri kanunla çizilmiş, modern bir aile olmuştur... Cumhuriyet rejiminin 1926 yılında, en medeni ve en demokrat memleketlerin kanunlarına bakarak ilan ettiği medeni kanun, eski devirdeki babalık aile şeklini bırakarak modern aile tipini kabul etmiştir.” (Sadak, 1939, s. 109. 110-112).

Necmettin Sadak bu düşüncelerini ders kitaplarında açıklarken, özellikle Atatürkçülük ile ilgili konularda, Mustafa Kemal'in kurmuş olduğu Cumhuriyet Halk Partisi programının maddelerinden hareket etmiş ve parti programı içerisinde yer alan inkılâp konusundaki düşüncelere yer vermiştir. Atatürkçü düşünce sisteminin önemi, Sadak’ın 1939 yılında yazmış olduğu sosyoloji ders kitabından önce, yani 1938 sosyoloji dersi programında da yer almıştır (Çimen, 1997).

1935 yılında sosyoloji programında yaşanan gelişmeler ve değişmeler bununla sınırla kalmayarak, 1957 programına kadar devam etmiştir. 1957 yılına kadar sosyoloji dersinde yaşanan gelişmeler şunlardır:

- 1937'de sosyoloji, Filozofi başlığı altında lise son sınıflarda Fen kolunda haftada üç saat, Edebiyat kolunda ise haftada yedi saat okutulmuştur. Fen kolunda iki saat sosyoloji, bir saat mantık, Edebiyat kolunda ise üç saat felsefe, iki saat mantık, iki saat sosyolojiye yer verilmiştir (Zabun, 2002, s. 28). Programda Filozofi başlığı altında verilen derslerin başlıca amaçları şu şekilde açıklanmıştır:

“...Liseyi bitirip hayata atılacak ve ya türlü türlü mesleklere girecek olan gençlere yeni hayat alanında Türk ulusunun ilerlemesine yarar genel içtimai ve fikri prensipleri kazandırmak ve onları kendi meslek ve san'atlerinin ötesini görebilir iş adamları ve memlekete yararlı yolda doğru düşünebilen yurttaşlar olarak yetiştirmek... filozofi derslerinin amaçlarından bir diğeri gençleri kalıplaşmış görüşlerden uzaklaştırmak ve olaylara geniş açıdan baktırmak, dünya harbinden sonra her yurttaşın gündelik hayatında önüne çıkan ekonomik sosyal vakıalar üzerinde düşünme melekesini kazandırmaktır” ( TC Kültür Bakanlığı, 1938, s. 12).

- 1942 yılında programın hem dili Öz Türkçeleşmiş hem de düzeni değiştirilmiştir. Önceleri sonda yer alan siyaset ve devlet konuları başa, ekonomik ve toplum bilimi konuları ise sona alınmış ve sona eklenen konulara Atatürk devrimine yönelik ilke eklenmiştir. Bu değişimlerin yanı sıra 1942 programında hukuk, siyasal bilim, tarih başlıkları toplumbilim konuları içerisinde yer almıştır (Tan, 1987). 
- 17 Eylül 1949’da, IV. Milli Eğitim Şurasında liseler dört yıla çıkartılmıştır. Liselerde yapılan bu değişiklik sonucunda, sosyoloji dersi Felsefe Dersleri içerisinde yer almıştır. Sosyoloji lisede Fen ve Edebiyat kolunda iki saat okutulmuştur. 1949 yılından sonra, Milli Eğitim Bakanlığı bir değişikliğe gitmiştir. Bu değişiklikle 24.7.1953'de yayınlanan bir genelgede, Edebiyat kolunda haftalık ders saatinin; 1/5'i mantık, 2/5'i felsefe, 2/5'i sosyoloji dersine, Fen kolunun haftalık ders saatinin ise; 1/3'ü mantık, 2/5'i sosyoloji dersine ayrılmıştır (Cicioğlu, 1985, s. 205; Çimen, 1997, s. 64).

- 1952 yılındaki programda, IV. Milli Eğitim Şurasında alınan kararla, liseler dört yıla çıkartılmıştır. 1952 lise programında, Filozofi-Sosyoloji felsefe dersi ismini alır ve ders lise dördüncü sınıflarında, Fen kolunda bir saat, Edebiyat kolunda iki saat okutulur (Beydoğan, 1988, s. 41; MEB, 1952, s. 72). Liselerde okutulan program, üç ana bölümden oluşmaktadır. Bunlar Cemiyet Olayları, Sitelere Kadar Cemiyetler ve İlerlemiş Cemiyetler'dir. Ayrıca programın sosyoloji anlayışında da, değişiklikler görülmüştür. Mesela programda toplum bilimi anlayışı, sosyoloji okumanın faydaları, alt bölümler halinde verilmiş ve programda açık bir şekilde ifade edilmiştir.

- 1954-1955 ders y1lında liselerde sosyoloji dersine, Fen ve Edebiyat kolunda iki saat yer verilmiştir (Tebliğler Dergisi, 1957:154). Bu yıllar içerisinde konularda her hangi bir değişiklik yapılmamıştır. Yani 1954-1955 yıllarındaki programlarda konular, 1952 yılında olduğu gibi üç ana başlıktan oluşmuştur (Tebliğler Dergisi, 1954, s. 110-111).

- 1956 yilında uygulamaya konulan program, 1954-1955 yıllarında uygulanan programdan farklı özellikler taşımaktadır. Bunun nedenleri arasında, liselerin dört yıldan tekrar üç yıla indirilmesidir. Liselerin üç yıla indirilmesi sonucunda, sosyoloji dersi Fen kolunda üç saat, Edebiyat kolunda altı saat okutulması yönünde kararlar alınmıştır (Beydoğan, 1988).

1935 yılından 1956 yılına kadar yapılan bu değişlikler sonucunda, yeni sosyoloji programının temelleri atılmıştır. Yeni sosyoloji programının temelleri, 21.9.1957 tarih ve 215 sayılı kararı ile kesinleşmiş ve 19571958 ders yılının başından itibaren de, okullarda okutulmuştur. Okullarda okutulan yeni programın bazı konuları, 1935 programında ele alınan konulara benzerlik göstermiştir. Bu konulardan biri Atatürkçülük ve Türk Kültürü konusudur. 1957 programında Atatürkçülük ve Türk Kültürü konularının amaç, içerik, yöntem-teknik boyutlarında nasıl ele alınarak yeni nesillere benimsetilmeye çalışıldığı Tablo 3'de gösterilmiştir.

\section{7 ve 1976 Sosyoloji Dersinde Atatürkçülük ve Türk Kültürü Konularına İlişkin Bulgular}

1957 ve 1976 sosyoloji dersinde Atatürkçülük ve Türk Kültürü konularına ilişkin bulgular Tablo 3'de yer almaktadır.

Tablo 3

1957 ve 1976 Sosyoloji Dersinde Atatürkçülük ve Türk Kültürü Konuları*

\begin{tabular}{|c|c|c|c|c|}
\hline Y1l & Konu & Amaç & İçerik (Muhteva) & Öğretim Yöntemi \\
\hline \multirow{6}{*}{1957} & \multirow{4}{*}{ Atatürkçülük } & \multirow{4}{*}{-} & İlerlemiş Cemiyetler* Ünitesi & \multirow{4}{*}{-} \\
\hline & & & $\begin{array}{l}\text { Millet gerçeği ve oluşu } \\
\text { (Türkiye'de millet anlayışının evrimi ve } \\
\text { milliyetçilik prensibi) }\end{array}$ & \\
\hline & & & $\begin{array}{l}\text { Devlet } \\
\text { (Eski devlet ve bugünkü devlet anlayış1; } \\
\text { demokrasi kavramı, demokrasilerde kanun ve } \\
\text { hürriyet nizamı) }\end{array}$ & \\
\hline & & & $\begin{array}{l}\text { Din hayatı } \\
\text { (Laiklik prensibi de izah edilecek, bu prensibin } \\
\text { türlü sosyal kurumlara etkisi üzerinde } \\
\text { durulacaktır.) }\end{array}$ & \\
\hline & & & Ilerlemiş Cemiyetler* Ünitesi & \\
\hline & Türk Kültürü & - & $\begin{array}{l}\text { Ailenin yapısı } \\
\text { (Kadının hukuki durumundaki gelişme de } \\
\text { incelenecek. Türk kadınlığının sosyal } \\
\text { durumundaki gelişmeden bahsedilirken ilgili } \\
\text { mevzuatımızda metin olarak faydalanılacaktır.) } \\
\text { Uygarlık ve Kültür }\end{array}$ & - \\
\hline
\end{tabular}


Tablo 3 -devam

\begin{tabular}{|c|c|c|c|c|}
\hline Y1l & Konu & Amaç & İçerik (Muhteva) & $\begin{array}{l}\text { Öğretim } \\
\text { Yöntemi }\end{array}$ \\
\hline & & $\begin{array}{l}\text { Türk Milletinin sosyal ve kültürel } \\
\text { mirasını kavramlarından imkân ve } \\
\text { zemin hazırlamak (Tebliğler } \\
\text { Dergisi, 1976) }\end{array}$ & & \\
\hline 1976 & Türk Kültürü & $\begin{array}{l}\text { Milli birlik ve beraberliğin dil, } \\
\text { kültür ve ülkü (ideal) birliğiyle sıkı } \\
\text { ilişkisine zaman zaman temas } \\
\text { firsatları aramaları, sosyal olayları } \\
\text { tarihi akışına da dikkat çekerek } \\
\text { öğrencilerin diğer derslerden elde } \\
\text { ettiği bilgilerden faydalanarak, } \\
\text { sosyolojinin verileriyle öğrencilerin } \\
\text { bilgilerinin genişletilmesine } \\
\text { gerektiği ölçüde yer vermeleri” } \\
\text { istenmektedir" (Tan, } 1987, \text { s. } 170)\end{array}$ & - & - \\
\hline
\end{tabular}

*T.C. Maarif Vekâleti, 1956; Tebliğler Dergisi, 7 Aralık 1957, s.183.

Talim Terbiye Kurulunun 21.9.1957 tarih ve 215 sayılı kararı ile 1957-1958 ders yılının başından itibaren, sosyoloji dersi liselerin 3.sınıfının Fen ve Edebiyat kollarında tekrar okutulmaya başlanmıştır. 30.9.1957 tarih 976 sayılı kararı ile sosyoloji programında; "sadece muhtevaya yer verilmiş olup, programın amaç, yöntem, teknik ve gerekçelerinin neler olduğu hakkında her hangi bir açıklamaya yer verilmediği ifade edilmektedir" (Beydoğan, 1988, s. 45). (Bkz: Tablo 3). 1957 programının muhtevası içerisinde; millet, devlet, aile vs. gibi konulara ek olarak, Atatürkçülük ve Türk Kültürü konularına da yer verilmiştir.

Tablo 3'de görüldüğü üzere, programda Atatürkçülük ve Türk Kültürü konuları şu şekilde ifade edilmiştir (MEB, 1970, s. 30; MEB, 1973, s. 37; T.C. Maarif Vekaleti, 1960, s. 30; Tebliğler Dergisi, 1959, s. 183):

Millet gerçeği ve oluşu (Türkiye'de millet anlayışının evrimi ve milliyetçilik prensibi)

Devlet. (Eski devlet ve bugünkü devlet anlayışı; demokrasi kavramı, demokrasilerde kanun ve hürriyet nizamı)

Din hayatı (Laiklik prensibi de izah edilecek, bu prensibin türlü sosyal kurumlara etkisi üzerinde durulacaktır.)

Ailenin yapısı. (Kadının hukuki durumundaki gelişme de incelenecek. Türk kadınlığının sosyal durumundaki gelişmeden bahsedilirken ilgili mevzuatımızda metin olarak faydalanılacaktır.

1957 yılında programında dönemin siyasi gelişmeleri etkili olmuştur. Bu siyasi gelişmelerden biri, 27 Mayıs Darbesidir. 27 Mayıs Darbesi hakkında 5 Eylül 1960 tarihli Tebliğler dergisinde şu açıklama yapılmıştır: "27 Mayıs inkılabı hakkında tarih, felsefe, yurttaşlık bilgisi gibi derslerin öğretmenleri birer konuşma yapacak, 27 Mayıs inkılabı ile kardeş kavgalarının önüne geçildiği anlatılacak, "inkılap şehitlerinin Türk Milletline verdikleri büyük misal üzerinde durulacak, milletin kendilerini kahraman Atatürk'ün yanında yer vermesinin manası belirtilecektir.”. 19 Eylül 1960 Tebliğler Dergisinde ise, 27 Mayıs darbesinin sosyoloji dersinde bütün öğretim boyunca işlenmesine ve 27 Mayıs inkılabı konusunda yazılı ödevlerin verilmesine, yönelik kararlar alınmıştır. Alınan kararlar 1960 hükümet darbesinden sonra hazırlanarak, 9 Temmuz 1961'de kabul edilen değişikliği ile devam etmiştir.

1961 anayasası sonrasında ders kitaplarında yeniden değişiklikler yapılmışıtır. Mesela 1957 yılındaki Osman Pazarlı'nın ders kitabında okuma parçaları; Laiklik ve Hukuk iken, 1961-1965'deki ders kitaplarında İnsan Hakları Beyannamesine yer verilmiş, aynı şekilde Cumhuriyet Sevgisi konusunun yerini de 1961 Anayasasının Genel Esasları, Laikliğin Batıda Ortaya Çıkıșı, Laikliğin Devlet ve Dinle İlişkisi konuları almıştır. Barışseverlik konusunun yerine ise 1965 yılında Akılcı Dünya ve Kemalizm konuları eklenmiştir (Çimen, 1997). 1957 yılından 1976 yılına kadar uygulamada kalan sosyoloji programının içeriğinde yer alan bu konuların dışında, programa yönelik bir takım kararlar alınmıştır. Bu kararlardan biri, 1974 de toplanan 9. Milli Eğitim Şurası kararlarıdır. 9. Milli Eğitim Şurasında, dört bölüm belirlenmiștir. Bunlar; Dil ve Edebiyat, Ekonomi ve Sosyal Bilimler, Matematik-Fizik ve Tabii Bilimlerdir. Dil ve Edebiyat ile Ekonomi ve Sosyal Bilimler bölümlerinde felsefe grubu dersleri olan felsefe, mantık, sosyoloji, psikoloji derslerine 6 saat yer verilirken, Matematik-Fizik ve Tabii Bilimler bölümlerinde ise, Mantık ve Sosyolojiye haftada üç saat yer verilmiștir (Cicioğlu, 1985). Ders saatlerindeki bu uygulamalar, 1976 programına kadar devam etmiştir. 
2.8.1976 tarih 319 sayılı Talim Terbiye Kurulu kararı ile lise son sınıflarda iki saat Sosyoloji dersine yer verilen yeni bir programa geçilmiştir. Yeni programa, bir önceki programın amaçlarını da kapsayacak şekilde, yeni amaçlar eklenmiştir. Bu amaçlar doğrultusunda, sosyoloji dersi programı dört bölümden oluşmuştur (Yazar, 2001, s. 19). Bunlar, sosyolojinin alanı, Sosyal Yapı, Sosyal Değişme, Uygulamalı Sosyolojiden örneklerdir. Bu bölümlerden Sosyal Yapı ünitesi içerisinde, Türk Kültürü konusuna yer verilmiş̧ir.

1978-1980 arasında iki yıl okutulan 1976 programı, 15.5.1978 tarihli ve 180 sayılı kararı ile kaldırılmış, yerine 1957 programı uygulamaya konulmuştur. Fakat 1976 programı, 15.4 .1980 ve 40 sayılı kurul kararı ile tekrar uygulamaya konulmuş ve 1986 yılına kadar uygulamada kalmıştır. (Tan, 1987; Tebliğler Dergisi, 1980). 1976 programının iki yıl uygulamadan kalarak, kaldırılmasının iki temel nedeni bulunmaktadır. Bunlardan birincisi, amaçları, ilkeleri, içerikleri, yöntemleri bakımından, günün koşullarına cevap vermediğidir. İkinci neden ise, programda kullanılan dilin öğrencinin seviyesine uygun olmaması gösterilmiştir (Beydoğan, 1988).

1986 yılına kadar yürürlükte kalan 1976 sosyoloji programında, Tablo 3'de görüldüğg̈ üzere, Atatürkçülük konusunda dolaylı ve dolaysız hiçbir gönderme yapılmasa da, Türk kültürü konusunda belli amaçlara yer vermiştir (Arslanoğlu, 2001; Tan, 1987). Bu amaçlar içerisinde, milli birlik ve beraberlik dil, kültür ve ülkü vs. gibi konular yer almıştır. Programın bu konuları yeni nesillere benimsetmesi için, okullarda Amiran Kurtkan'nın kitabı okutulmuştur. Kurtkan'nın kitabı, bu güne kadar liselerde okutulan ders kitaplarından farklı özellikler taşımaktadır. Mesela Kurtkan kitabında siyasetle ilgili bilgiler yerine bilimsel bilgilere yer vermiştir. Buna karşın, kitap uzun süre ders kitabı olarak okutulmamıştır. Çimen'e (1997) göre, bunun nedeni kitap dilinin ağır olması ve yeni sosyoloji öğrenen bir öğrenci için konuların anlaşılmasının zor olmasıdır. Bu eleştirilere rağmen, Kurtkan'nın önemle üzerinde durduğu konularından biri, Türk Kültürü olmuştur. Kurtkan kitabında, Türk Kültürü konusuna şu şekilde değinmiştir:

“...Manevi kültürün önemli unsurlarından biri olarak örf ve adetleri birlik şuuru aşllayan değer hükümlerini ihtiva eden milletler bu değer hükümlerine gereken önemi verdikleri takdirde nüfusun sosyal olgunluğa erişebilmesi ve sosyal gelişmenin gerçekleştirilmesi bakımından çok müsait bir kültür hazinesinden yararlanmış olurlar. Türk örf ve adetleri birlik ve bütünlük değer hükmüne dayanmaları bakımından bu hususta son derece önemli bir rol ifa edebilecek özelliktedir. Bu özellikten yararlanıldığı takdirde beyin göçüde önlenerek kültürümüzün zenginleşmesi daha kolaylıkla mümkün olabilecektir.” (Kurtkan, 1980, s. 119-120).

“...Türkler istismarcı bir kültüre sahip olmadıkları için ne ana vatanda ve ne de yayıldıkları topraklarda hiçbir zaman istismar hedefi gütmemiştir...'Türk kültürü, fert ve cemiyetlerin bir madalyonun iki yüzü gibi aynı realitenin iki ayrı görünüşü olduğunu öne süren modern sosyolojinin görünüşlerine uygun olarak, fert ve cemiyet menfaatlerini uzaklaştırmış, dengelemiş ve fertlerin cemiyet karşısında küskünlük değil sevgi ve fedakarlık hisleri duyabilmelerini teşvik etmiştir." (Kurtkan, 1980, s. 132-133).

1976 yılında ders kitaplarında görüldüğü gibi, Türk Kültürü konusunda bir takım bilgiler yer alırken, Atatürkçü düşünce konusunda dolaylı ve dolaysız hiçbir gönderme yapmamıştır (Bkz: Tablo 2). Mesela dönemin İkinci Milliyetçi Cephe Hükümeti (1977-1978) Türk milletinin manevi değerlerini benimseyen, koruyan, geliştiren, milletini seven bireyler yetiştirmek istemişler ve bu düşüncelerini hazırladıkları programlara yansıtmışlardır. İkinci Milliyetçi Cephe Hükümetinin (1977-1978) eğitim programında yer alan bu düşünce, Birinci Milliyetçi Cephe Hükümetinin eğitim programında yer alan ifadeye benzemektedir. Kaplan'a (2002) göre, İkinci Milliyetçi Cephe Hükümetinin eğitim programılla yetiştirilmek istenilen bireyin tanımını şu şekildedir:
"Yetiştirilecek bireyin tanımı yapılırken... Atatürk İnkılaplarına ve Türk Milliyetçiliğine bağlı; ibaresinin ve Türkiye Cumhuriyeti'nin 'insan haklarına milli, demokratik, laik, sosyal bir hukuk devleti olan' şeklinde sıfatlarının...' çıkarılmış olmasıdır... Hükümet, sosyal bilimlere ilişkin ders kitaplarının yeniden yazılacağını ilan eder. Yeni nesillere dünya görüşü aşılamakta önemli rol oynayan, bilhassa ahlak, sosyoloji, felsefe ve psikoloji gibi derslerin kitapları evlatlarımızın milli inançlarını, manevi değerlerini tahrip edici değil, bilakis milli ve manevi değerlere bağlılığı temin edici şekilde yeniden yazılacaktır." (Kaplan, 2002, s. 254).

Partinin eğitim programında yer alan bu açıklamalarda görüldüğü üzere, 1976 programında ele alınan Türk Kültürü konuları dönemin hükümetinin eğitim programlarında da önemle üzerinde durulan konuların başında gelmiştir. Buna karşın, 1976 programında Atatürkçülük konuları konusunda dolaylı ve dolaysız bir bilgi bulunmamaktadır. 1980 yılından sonra Atatürkçülük konularına geniş yer verilmiştir. Amaç "Atatürkçü düşünce sistemini benimseyen, Atatürkçü olarak yetiştirilen, Atatürkçülüğü davranış haline getiren" bireyler yetiştirmektir. Bu amacı gerçekleştirmek için de Milli Eğitim Bakanlığı Atatürk İnkılâp ve İlkelerine yönelik bir yönergeyi okullara iletmiştir. Okullarda iletilen bu yönerge, sadece İnkılap derslerinde değil, bütün derslerde uygulanmaya ve öğrencilerin Atatürkçü olarak yetiştirilmelerine yöneliktir (Çimen, 1997, s. 109). Sosyoloji dersinde de, bu yönergenin belirlemiş olduğu öğrenci modelini yetiştirmek için, İlerlemiş Toplumlar ünitesinin 
Millet konusunda; Atatürk'ün millet anlayışı ile milliyetçilik, halkçılık, devletçilik ilkelerine, Atatürk'ün din konusundaki düşüncelerine, Türk ailesine, Türk kadınına ayrıntılı bir şekilde yer verildiği ders kitaplarında görülmektedir. 1980 sonrası sosyoloji ders kitaplarının diğer bir özelliği, İstiklal Marşının ve daha sonraki sayfaya Atatürk'ün Gençliğe Hitabesi’nin konulmasıdır (Çimen, 1997).

\section{Sosyoloji Dersinde Atatürkçülük ve Türk Kültürü Konularına İlişkin Bulgular}

1986 sosyoloji dersinde Atatürkçülük ve Türk Kültürü konularına ilişkin bulgular Tablo 4’te yer almaktadır.

Tablo 4

1986 Sosyoloji Programında Atatürkçülük ve Türk Kültürü Konuları*

\begin{tabular}{|c|c|c|c|}
\hline Konu & Amaç & İçerik (Muhteva) & $\begin{array}{l}\text { Öğretim } \\
\text { Yöntemi } \\
\end{array}$ \\
\hline Atatürkçülük & - & $\begin{array}{l}\text { Sosyal Yapı Ünitesi } \\
\text { Millet } \\
\text { Atatürkçü düşüncede millet anlayışı } \\
\text { Milletti meydana getiren unsurlar } \\
\text { Milletin tanımı } \\
\text { Milli ahlaka uygun hareket etme } \\
\text { Atatürkçü düşünce sisteminde milliyetçilik } \\
\text { Millet ve milliyetçilik } \\
\text { Atatürkçü düşüncede sosyal kültürel milli güç } \\
\text { Atatürkçü düşüncede kadının Türk toplumundaki yeri } \\
\text { Atatürkçü düşüncede dayanışmanın toplum hayatındaki } \\
\text { önemi }\end{array}$ & $\begin{array}{l}\text { Düz anlatım } \\
\text { yöntemi }\end{array}$ \\
\hline Atatürkçülük & - & $\begin{array}{l}\text { Din } \\
\text { Laikliğin genel esasları ve temel amaçları } \\
\text { Din ve Laiklik } \\
\text { Atatürkçü düşüncede laiklik kavramı } \\
\text { Din konusunda; Atatürkçü düşüncede laiklik kavramı } \\
\text { Ekonomi } \\
\text { Türklerde ekonomik düzen ve Atatürk'ün görüşleri } \\
\text { Atatürkçü düşünce sisteminde insanın yeri } \\
\text { Atatürkçü Düşünce Sistemi } \\
\text { Atatürkçülügün tanımı ve önemi, amacı } \\
\text { Atatürkçülüğün nitelikleri } \\
\text { Atatürkçü düşünce siteminin diğer düşünce sistemleri ile } \\
\text { mukayesesi }\end{array}$ & $\begin{array}{l}\text { Düz anlatım } \\
\text { yöntemi }\end{array}$ \\
\hline Türk Kültürü & $\begin{array}{l}\text { Türk Milletinin sosyal } \\
\text { ve kültürel mirasını } \\
\text { kavramalarında imkan } \\
\text { ve zemin hazırlamak } \\
\text { Dünyadaki diğer } \\
\text { cemiyetlerin sosyal ve } \\
\text { kültürel yapılarını daha } \\
\text { iyi tanıyabilmeleri için } \\
\text { gerekli zemini } \\
\text { hazırlamak } \\
\text { Külttür unsurları } \\
\text { arasındaki ilişkiyi } \\
\text { görmelerini sağlayarak } \\
\text { şahsiyet bütünlüğü } \\
\text { sağlamak. }\end{array}$ & $\begin{array}{l}\text { Sosyal Yapı Ünitesi } \\
\text { Türk Kültürünün Genel Nitelikleri } \\
\text { Devamlılık ve yaygınlık } \\
\text { Demokrasiye açık olmak } \\
\text { Teşkilatç1lığa elverişli olmak } \\
\text { Adaleti yerleştirmek ve yaymak } \\
\text { Maddi ve manevi fedakarlık } \\
\text { Kültür ve Sosyal Kurumlar } \\
\text { Kültürün tarifi } \\
\text { Kültürün kazanılması } \\
\text { Kültürel Unsurlar Açlsından Temel Sosyal Kurumlar } \\
\text { Türklerde aile }\end{array}$ & $\begin{array}{l}\text { Düz anlatım } \\
\text { yöntemi }\end{array}$ \\
\hline
\end{tabular}

\footnotetext{
*Beydoğan, 1988; Tebliğler Dergisi, 1981, s.37
}

1981-1982 yılında sosyoloji dersi, Felsefe grubu (Felsefe-Sosyoloji-Mantık) dersleri içerisinde yer almıştır. Sosyoloji dersinin felsefe grubu dersleri içerisinde yer alması, Fen ve Edebiyat kollarındaki ders saatini değiştirmemiştir. Yani sosyoloji Fen ve Edebiyat kollarında iki saat okutulmasına devam edilmiştir. Ayrıca, 
1.12.1981 tarih 2104 sayılı Tebliğler dergisinde alınan kararla, 1986 programına da hazırlık olması açısından, Atatürkçülük konusuna sosyoloji dersinde yer verilmiştir. Bu kararlar, 1.12.1981 tarih 2104 sayılı Tebliğler dergisinde “...Konular işlenirken yeri geldikçe Atatürk ilke ve görüşleri ile bağlantı kurulmalı; konuların ilgisine göre gerekli açıklamalar yapılmalıdır." şeklinde ifade edilmiş ve bu ifade doğrultusunda şu ilkelere yer verilmiştir (Tebliğler dergisi, 1981, s. 37):

Millet konusunda, Atatürk'ün '’Millet', anlayışı ve Milliyetçilik ilkesi.

Devlet konusunda, Atatürk'ün 'Devlet' anlayışı Cumhuriyetçilik, Halkçılık, Devletçilik ilkeleri.

Din hayatı konusunda, Atatürk'ün Laiklik ilkesi, Laikliğin dinsizlik olmadığı, Atatürk'ün İslam dinine verdiği önem.

Kültür ve Medeniyet konusunda, Atatürk'ün bütünleyici ilkelerinden Bilimsellik, Akılcılık, Çağdaşçılık ve Batılılaşma ilkeleri ile Atatürk'ün Sanat ve sanatçıya verdiği önem.

Belirtilen ilkeler doğrultusunda, liselerde sosyal bilimler alanında eğitim gören öğrencilere verilen sosyoloji dersi amaç, muhteva, yöntem ve uygulama ilkeleri bakımından yeniden düzenlenmiştir. Bu düzenlemeler yapılırken, Türk toplumunun yapısı, kültürel değişmeleri, Atatürk ilke ve inkılâpları ile kaynaştırılarak verilmeye çalışılmış ve muhteva bu düzenlemeler doğrultusunda hazırlanılmıştır (Beydoğan, 1988). Yapılan düzenlemeler 16.01.1986 tarihli ve 1 sayılı Talim Terbiye kararı ile felsefe grubu öğretim programlarında uygulanmıştır. Çünkü 12.5.1986 tarih ve 102 sayılı kararı ile liseler için hazırlanan haftalık ders çizelgesinde sosyoloji adı bulunmamıştır. Sosyoloji, felsefe grubu dersleri içerisinde yer almış ve Fen ve Matematik alanlarında haftada üç saat, Edebiyat alanlarında ise, haftada altı saat okutulmuştur. Bu uygulama kredi ve ders geçme sisteminin uygulamaya konulduğu 1992 yılına kadar devamlılığını korumuştur (Arslanoğlu, 2001). Uygulamada olduğu süre içerisinde, programda Atatürkçülük konusu, yeni nesillere daha önceleri uygulanmış olan programlardan farklı bir biçimde ele alınarak, kavratılmaya çalışılmıştır. Mesela, 1935 ve 1942 programları Atatürk inkılâplarını tek tek ele alarak açıklamış, 1986 programı ise, Atatürkçü düşüncenin özelliklerini belirleyerek, bunları ders konuları haline getirmiştir (Bkz: Tablo 4).

Tablo 3'de görüldüğü üzere, sosyal yapı ünitesinde, Atatürkçülük konusunda şu içerikler yer almıştır (Tan, 1987, s.174; Zabun, 2002, s. 38-39):

Atatürkçü düşüncede millet anlayışı,

Atatürkçü düşüncede millet ve yurt sevgisi,

Atatürkçü düşünce sisteminde milliyetçilik,

Atatürkçü düşüncede sosyal ve kültürel milli güç,

Atatürkçü düşüncede kadının Türk toplumundaki yeri ve hakları,

Atatürkçü düşüncede laiklik kavramı,

Türkiye'de ekonomik düzen ve Atatürk’ün görüşleri,

Atatürkçü düşüncede insanın yeri,

Atatürkçü düşünce sisteminin diğer düşünce sistemleriyle karşılaştırılması

Gene ilk kez bu programda Türk kültürünün genel niteliklerinin tanıtıldığı bir bölüme yer verilmiştir.

1986 programının muhtevasında Atatürk ilke ve inkılâplarına ek olarak, program ilk defa muhtevaya, Türk Kültürünün Unsurları adlı bir bölümü eklemiştir (Beydoğan, 1988, s. 54). Aynı zamanda programda, açıklamalar kısmında öğretmenin ders işleniş esnasında yapması gerekenlerin neler olduğu açıklamış ve daha çok anlatım yöntemine yer verilmiştir. Mesela öğretmen 1986 programında "Niçin sosyoloji okuyoruz? Atatürk konusunda telkinlerde bulunacak vs. konusunu sosyolojinin amaçlarını ifade edecek şekilde anlatacaktır.”. Bunlara ek olarak programda, Türkçenin yaşayan, canlı, tabii ve zengin olma özelliği, barışçılığın medeniyete etkisi, Türk İnkılâbının uygulama dönemi, Türk İnkılabı ve sonuçları konularının ev ödevi olarak verilmesi istenmiştir (Beydoğan, 1988; Zabun, 2002).

1991-1992 yılına gelindiğinde, liselerde kredili sisteme geçilmiştir. Kredili sistem ile birlikte öğrencilere seçmeli ve ortak dersler verilmiştir. Kredili sistemde bu uygulamanın temel amaçlardan biri, öğrencinin ilgi, ihtiyaç ve yeteneğine uygun dersi seçme hakkının tanınmasıdır (Çimen, 1997). Liselerde seçmeli ders olarak okutulan derslerden biri sosyolojidir. 1991-1992 yıllarında sosyoloji 1981-1982 yıllarında olduğu gibi, felsefe grubu dersleri içerisinde yer almıştır. Felsefe grubu dersleri olan sosyoloji, felsefe, mantık, Fen ve Matematik kollarında eğitim gören öğrenciler için seçmeli iken, Sosyal Bilimler ve Edebiyat kollarında okuyan öğrenciler 
için, haftada iki saat zorunlu dersler olmuştur. Felsefe grubu dersleri içerisinde yer alan sosyoloji dersinin amaçları, içeriği, öğrenme-öğretme durumları ve değerlendirme boyutları programın yetiştirmek istediği insan modeline göre oluşturulmuştur. Yetiştirilmek istenen insan modeline göre, sosyoloji dersinde bazı konulara önem verilmiştir. Sosyoloji dersinin üzerinde durduğu konulardan biri, Atatürkçülük diğeri ise, Türk Kültürüdür. Bu konular 1991-1992 yılından sonra uygulamaya konulacak olan 1995 sosyoloji programında, ayrıntılı bir biçimde ele alınmıştır (Bkz: Tablo 5).

\section{Sosyoloji Dersinde Atatürkçülük ve Türk Kültürü Konularına İlişkin Bulgular}

1995 sosyoloji dersinde Atatürkçülük ve Türk Kültürü konularına ilişkin bulgular Tablo 5’te yer almaktadır.

Tablo 5

1995 Sosyoloji Programinda Atatürkçülük ve Türk Kültürü Konuları*

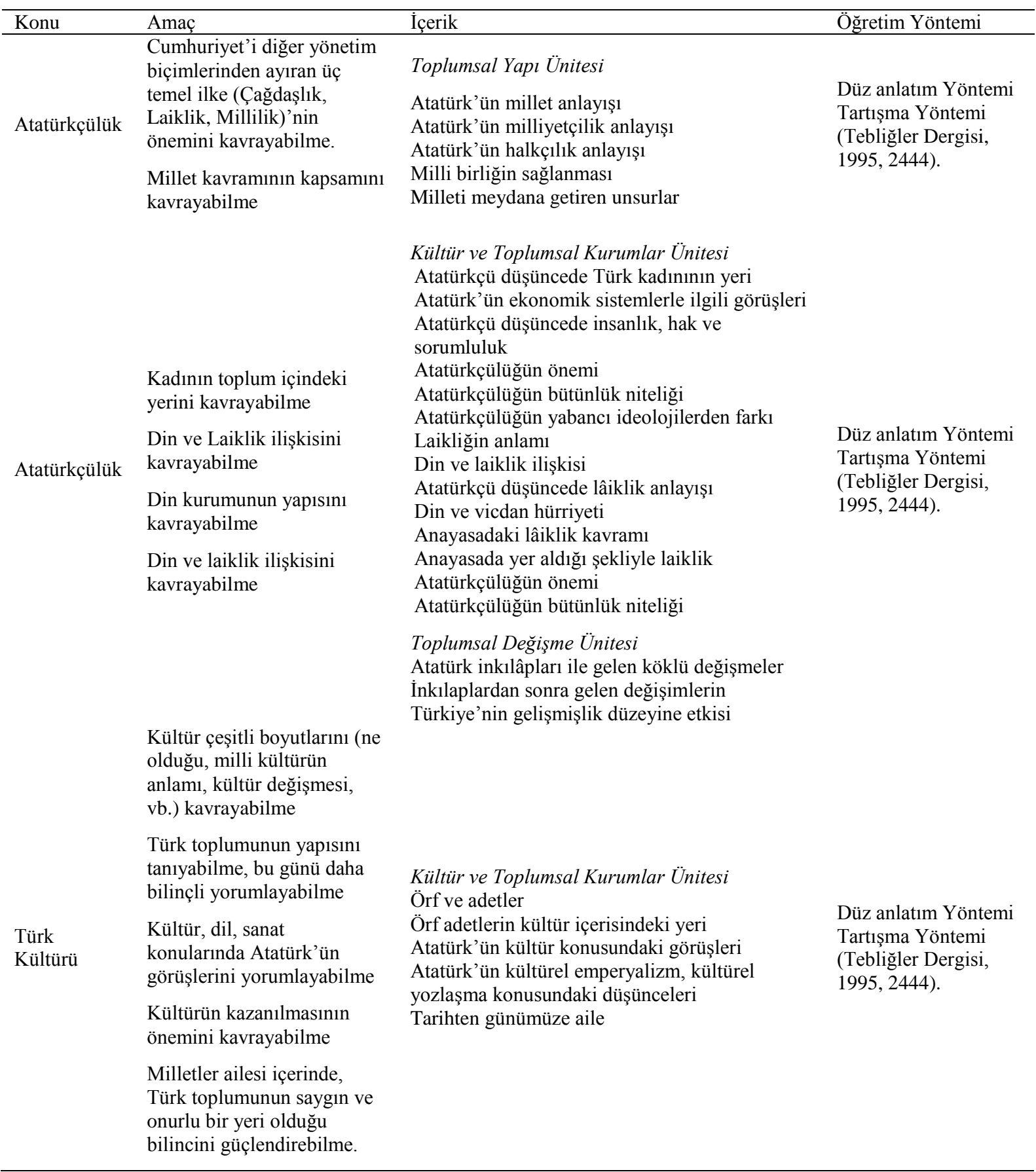

* Merter ve Ylldiz, 2010, s.18

1992 kredili sistemin uygulandığı yıldan sonra, yeni bir sosyoloji programı hazırlanmıștır (Merter ve Yıldız, 2010:18). Yeni sosyoloji öğretim programı 01.11.1995 tarihli ve 353 sayılı Talim Terbiye Kurulu kararı ile kabul 
edilmiş, 04.12.1995 tarihli 2444 sayılı Tebliğler dergisinde yayınlanmıştır (Yazar, 2001). 1997-1998 öğretim yılından itibaren ise, okullarda uygulanmak üzere kabul edilmiştir (Arslanoğlu, 2001). Kabul edilen program, Milli Eğitim Bakanlığı Talim Terbiye Kurulu Başkanlığı 19.8.1998 tarih ve 174 sayılı kararı ile, ortaöğretim kurumlarının 9., 10., 11. ve 12. sinıflarının sosyal bilimlerin alan dersleri arasında iki saatlik zorunlu ders, Fen Bilimleri, Türkçe-Matematik, Yabancı Dil, Sanat ve Spor alanlarıyla, Fen liselerinde iki saat seçmeli ders olarak okutulması uygun görülmüştür (Zabun, 2002). Okullarda okutulmak üzere gönderilen 1995 sosyoloji öğretim programının açıklamalar bölümünün içeriği hazırlanırken, sadece Türkiye'de değil, dünyada yaşanan gelişmelerin de göz önüne alınarak hazırlandığı belirtilmiştir. Bu programda içerik, amaçlardan yola çıkılarak Sosyolojiye Giriş, Toplumsal Yap1, Kültür ve Toplumsal Kurumlar, Toplumsal Değişme ünitelerinden oluşmaktadır. Tablo 5'te görüldüğü üzere, 1995 programının içeriğinde, Atatürkçülük ve Türk Kültürü konularının hangi üniteler içerisinde yer aldığı gösterilmektedir. Bu üniteler Toplumsal Yap1, Kültür ve Toplumsal Kurumlar, Toplumsal Değişme üniteleridir. Mesela Türk Kültürü konusu Kültür ve Toplumsal Kurumlar ünitesinde şu şekilde açıklanmıştır:

“...Türkiye Cumhuriyeti’nin temeli kültürdür. Sözü, kültüre verdiği önemi belirtir. Onun bu konudaki amacı bir kültür değişmesi yapmak ve yeni Türk insanın yetiştirecek Türk Kültürünü yaratmaktır. Oluşturmak istediği kültürü şöyle tanımlar: bir milli eğitim programından söz ederken, eski devrin boş inançlarından ve yaradılış niteliklerimizle hiç de ilgisi olmayan yabancı fikirlerden, doğrudan ve batıdan gelebilen bütün etkilerden tamamen uzak, milli karakterimiz ve tarihimizle uyumlu bir kültür kastediyorum. Çünkü milli dehamızın tam olarak gelişmesi, ancak böyle bir kültür ile sağlanabilir.” (Erdem, 2003, s. 99-100).

Aynı ünite içerinde, Atatürkçülük konusunda ise şu ifadelere yer vermiştir:

“...Laik devlet sistemlerinde 'din kamu hizmeti olarak kabul edilemez. Laik düzenlerde 'devlet dini” söz konusu olamaz" (Erdem, 2003, s. 127). "Atatürkçülüğün önde gelen özelliklerinden biri insan sevgisidir... Atatürk'ün akılcı, eşitlikçi, toplumcu, insanc1l, özellikleriyle ulus, yurt, devlet yönetimi uluslar arası ilişkiler hakkındaki düşünce ve eylemleri bir bütünlük oluşturur. Buna Atatürkçü düşünce sistemi, kısaca Atatürkçülük diyoruz.” (Erdem, 2003, s. 157-158).

1995 programı öğretim yöntemleri konusunda incelediğimizde, Tablo 5’te görüldüğü üzere, iki yönteme yer verilmiştir. Bunlar anlatım ve tartışma yöntemidir.

\section{Sosyoloji Dersinde Atatürkçülük ve Türk Kültürü Konularına İlișkin Bulgular}

2009 sosyoloji dersinde Atatürkçülük ve Türk Kültürü konularına ilişkin bulgular Tablo 6'da yer almaktadır. Talim Terbiye Kurulunun 14.12.2009 tarih ve 237 say1l kararı ile kabul edilen program genel liselerin 9., 10., 11., 12. sınıflarında iki saat okutulmuştur (Tebliğler Dergisi, 2009, s. 1585). Yeni kabul edilen program, 1995 programından farklı özellikler taşımaktadır. Bunlardan biri 1995 programında Sosyolojiye Giriş (\% 15), Toplumsal Yapı (\% 35), Kültür ve Toplumsal Kurumlar (\% 35), Toplumsal Değişme (\% 15), üniteleri yer alırken, 2009 programında, Sosyolojiye Giriş (\% 8), Birey ve Toplum (\% 14), Toplumsal Yap1 (\% 10), Toplumsal Değişme ve Gelişme (\% 17), Toplum ve Kültür (\% 17) ve Toplumsal Kurumlar (\% 34) ünitelerine yer verilmiştir. 2009 programındaki üniteler içerisinde özellikle Toplum ve Kültür, Toplumsal Kurumlar ünitelerinde Atatürkçülük ve Türk Kültürü konularına geniş yer verilmiştir. Atatürkçülük ve Türk Kültürü konusunun yoğun bir şekilde verildiği bu ünitelerin kazanım sayılarına ve ders saatine baktığımızda Toplum ve Kültür ünitesinin kazanım sayısı sekiz, ders saati 12, Toplumsal Kurumlar ünitesinin kazanım sayısı 22, ders saati 25'dir. Başka bir deyişle, Atatürkçülük konusunun yer aldığı, Toplumsal Kurumlar ünitesinin diğer üniteler içerisindeki oranının fazla olduğu söylenebilir. Buna karşın, 2009 programında Atatürkçülük ve Türk Kültürü konularının yer aldığı ünitelerin oranları, 1995 programında bu konuların yer aldığı ünitelerdeki oranlarından az olduğu görülmektedir. Yani 1995 programında Atatürkçülük ve Türk Kültürü konularına ünitelerde ayrılan oran, 2009 programındaki ünitelere ayrılan orandan fazladır. Fakat 2009 programında görülen bu değişime karşın, ünitelerde Atatürkçülük ve Türk Kültürü konularına geniş yer verilmiş ve okullarda okutulan ders kitaplarında bu konuların yeni nesillere benimsetilmesi amacıyla, bir takım düzenlemeler yapılmıştır. Mesela, 2009 yılındaki ders programında Atatürkçülük ve Atatürkçü düşünce sistemi 1995 programında yapılan tanımdan farklı bir şekilde tanımlanmış.

“...Atatürkçülük bir sistem olarak, bir hedefi ve bir hedefe ulaşmak için kendine özgü bir stratejiye sahiptir. Atatürkçü düşünce sisteminin hedefi, Türk milletini çağdaş uygarlık seviyesine ulaştırmaktır. Bu hedefe ulaşmak için izlediği strateji ise, ne batı dünyasının vahşi kapitalist yöntemi ile ne de doğu dünyasının insan hak ve özgürlüklerini ortadan kaldırıp yeni bir kölelik düzeni getiren kolektivist sistemle uyuşur. Çünkü bu iki sistemde de insanın doğasına uymayan aşırılıklar vardır. Birincisi, insan benciliğinin en had safhaya ulaşmasıdır, ikincisi de insanı köleleştirmek pahasına, devlet egosunun en had safhaya ulaşmasıdır. Dolaysıyla, 
Atatürkçü düşünce sistemi, bu ikisinin de dışında, apayrı bir sistem ve strateji özelliği taşır."

(MEB, 2009, s. 161-162).

Tablo 6

2009'da Hazırlanan Sosyoloji Programında Atatürkçülük ve Türk Kültürü**

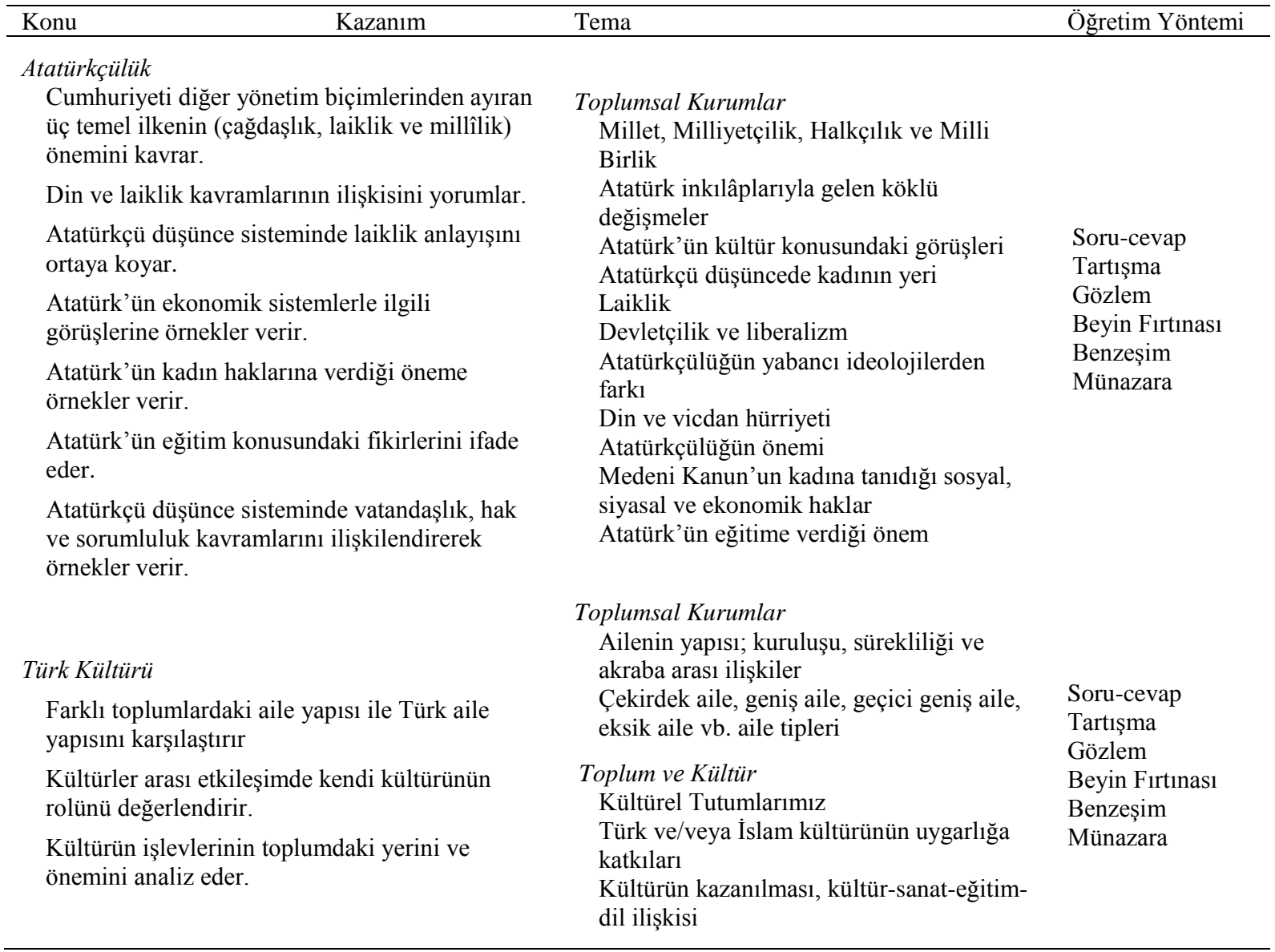

*MEB, 2009

Türk Kültürü konusunda Atatürk’ün düşüncelerinden örnekler verilmiştir:

“Türkiye Cumhuriyeti’nin temeli kültürüdür. Bu sözü burada ayrıca izaha lüzum görmüyorum. Çünkü bu, Türkiye Cumhuriyeti'nin okullarda birçok vesilelerle eser halinde tespit edilmiştir.. Sanatsız kalan bir milletin hayat damarlarından biri kopmuş demektir."

“... Atatürk dini politika aracı olmaktan kurtarıp hak ettiği konumda görmek ister. Çıkarcılığın kaynağı olan siyasetten uzaklaştırmaya çalışır.” (MEB, 2009, s. 88-140).

2009 programına uygun hazırlanan ders kitaplarında Atatürkçülük konusu ele alınırken, 2488 sayılı Tebliğler Dergisindeki bir takım kararlar dikkate alınmıştır. Bunlar:

“...Atatürkçülük konuları ele alınırken 2488 sayılı Tebliğler Dergisinde yayınlanan Orta Öğretim Kurumlarının Öğretim Programları ile Ders Kitaplarında Yer Alması Gereken, Atatürkçülük ile İlgili Konuları esas alınmalıdır.” (MEB, 2009, s. 7).

“...Atatürkçülükle ilgili Konular büyük ölçüde derslerin alan bilgisi konuları ile kaynaştırılmaya çalışılmıştır... Ayrıca, Atatürkçülükle ilgili Konular yazılırken, davranışların arka arkaya sıralanması şeklinde metin oluşturma yoluna gidilmemelidir... Atatürkçülükle ilgili Konuların ortaöğretim kurumlarını kapsayan konuları yürürlükten kaldırılarak yerine burada hedef, davranış ve açıklamalar şeklinde belirtilmiş olan Atatürkçülükle İlgili Konular uygulamaya konulmuştur.” (Tebliğler Dergisi, 1998, s. 588).

Yukardaki açıklamalarda görüldüğü üzere, 2009 programı birçok yönü ile diğer programlardan da farklı özellikler taşımaktadır. Bu farklılıklar içerisinde en dikkati çeken programın öğrenci merkezli eğitim anlayışını benimsemedir. Yani program öğrencinin gelişimsel özellikleri doğrultusunda araştırma yapmasını, bilgiyi yapılandırmasını ve yaparak-yaşayarak öğrenmesini amaçlamaktadır. Mesela, Atatürkçülük konusunun geniş yer 
verildiği Toplumsal Kurumlar ünitesi içerisinde yer alan Yaşasın Demokrasi! Yaşasın Cumhuriyet! etkinlik örneği, 2629 sayılı Tebliğler dergisinde yapılan değişiklikle şu şekilde ifade edilmiştir:

"Öğrencilerden tarihte görülmüş farklı yönetim şekilleriyle ilgili bir araştırma yapmaları istenir. Araştırma sonuçları siyasal yönetimlerin benzerlik ve farklılıkları dikkate alınarak gruplandırılır. Gruplandırılmış olan bu yönetim şekilleri günümüzde geçerli olan demokrasinin kurum ve kuruluşları açısından dikkate alınarak birey, toplum, devlet ilişkisi ortaya konulur.” (Tebliğler Dergisi, 2010, s.137).

2010 yllında yayınlanan 2629 sayılı dergide özellikle programın öğrenmeyi öğrenme yolunda öğrenciyi merkeze aldığı ve öğretmen rehberliğinde öğrenmesini gerçekleştirdiği görülmektedir. Örneğin, program daha önceki programlarda yer alan "Öğretmen bilgi-iletişim teknolojilerini derste kullanabilir." ifadesini "Öğretmen bilgiiletişim teknolojilerini derste kullanmalıdır." şeklinde ele almıştır. Başka bir deyişle, öğretmenin öğrencide istendik davranışları kazandırması için, öğrenme-öğretme sürecinde farklı araç-gereçlerden yararlanması koşulu getirilmiştir. Böylece 2009 programı, 21.yüzyılda yetiştirilmek istenen insan modelini (bilgiyi seçen, bilgiyi yapılandıran, yaratıcı, problem çözen vs.) elde etmek amacıyla diğer programlardan farklı uygulamalar, etkinlikler, yöntem-teknikler ve araç-gereçler kullanılmak istenmiştir.

\section{Sonuç ve Tartışma}

Atatürkçülük ve Türk Kültürü konuları 1924-2009 yılları arasında farklı şekillerde ele alınmış ve bu farklılıklar günün programlarına yansımıştır. Bu yansımalara bakıldığında, 1924 programında Atatürk İlke ve İnkılâplarının bu dönem içerisinde yürürlüğe girmemesi nedeniyle Atatürkçülük ve Türk Kültürü konularına yer verilmediği görülmüsşür. 1935 sosyoloji dersi öğretim programının en önemli özelliği, dersin adının sosyoloji olarak değiştirilmesidir. Programın 1924 programından farkı, Atatürkçülük ve Türk Kültürü konularını tek tek ele alarak ayrıntılı bir şekilde incelemesidir. Diğer bir özelliği ise, güncel olan bazı toplumsal sorunları sorgulamasıdır. 1957 programına bakıldığında ise, amaç, muhteva, yöntem-teknik öğeleri içerisinde en fazla muhteva ön plana çıkartılmıştır. Programda Atatürkçülük ve Türk Kültürü konularına yönelik olarak da muhtevada milliyetçilik prensibi, laiklik prensibi, kadın hakları vs. gibi konulara değinilmiştir. Aynı zamanda programda, Atatürkçülük ve Türk Kültürü konusu dışında günün koşulları içerisinde yaşanan siyasi gelişmelere de yer verilmiştir. 1976 sosyoloji programı amaçlarına bakıldığında ise, ilkeleri, içerikleri, yöntemleri bakımından günün koşullarına cevap vermemesi, dilinin öğrenci düzeyine uygun olmaması nedeniyle iki yıl sonra uygulamadan kaldırılmıştır. Bu süre içerisinde, gerek programda gerekse ders kitabında Atatürkçülük konularına yönelik dolaylı ve dolaysız herhangi bir bilgiye yer verilmemiştir. Buna karşın, Türk Kültürü konusuna geniş yer verildiği sonucuna ulaşılmıştır.

1986 programı, Atatürkçülük ve Türk Kültürü konularını yoğun bir şekilde ele almıştır. Program bu sebepten dolay1; amaç, muhteva, yöntem ve uygulama ilkeleri yönünden tekrar düzenlenmiştir. Bu düzenlemeler doğrultusunda, muhtevaya Türk Kültürünün Unsurlar eklenmiştir. Türk Kültürünün Unsurları içerisinde özellikle aile Türklerde aile, Ailenin Kutsallığı, Aile bireyleri arasında dayanışma gibi konulara değinilmiştir.

1995 sosyoloji programına baktığımızda, içeriğinde Atatürkçülük ve Türk Kültürü konularının Toplumsal Yapı, Kültür ve Toplumsal Kurumlar, Toplumsal Değişme ünitelerinde yer aldığı görülmüştür. Belirtilen bu ünitelerin program içerisindeki payına baktığımızda; Toplumsal Yapı \% 35 (Atatürk'ün millet anlayışı, Atatürk'ün milliyetçilik anlayışı, Atatürk'ün halkçıllı anlayışı, Milli birliğin sağlanması), Kültür ve Toplumsal Kurumlar \% 35 (Atatürk'ün kültür konusundaki görüşleri, Atatürkçü düşüncede Türk kadınının yeri, Atatürkçü düşüncede lâiklik anlayışı, Din ve vicdan hürriyeti Anayasadaki lâiklik kavramı, Atatürk'ün ekonomik sistemlerle ilgili görüşleri, Atatürkçü düşüncede insanlık, hak ve sorumluluk, Atatürkçülüğün önemi, Atatürkçülüğün bütünlük niteliği, Atatürkçülüğün, yabanc1 ideolojilerden farkı), Toplumsal Değişme \% 15 (Atatürkçü düşüncede toplumsal dayanışma, Atatürk inkılâpları ile gelen köklü değişmeler)'dir (Tebliğler Dergisi, 1995, s. 759; Yazar, 2001, s.23). Görüldüğü üzere, 1995 programı 1986 programına çok benzemektedir. Fakat aralarında bir takım farklılıklar bulunmaktadır. Bu farklılıklardan biri ünite isimleri, diğeri ise ünitelerin program içerisindeki oranlarıdır. Yani 1986 programında Atatürkçülük ve Türk Kültürüne ayrılan oran \% 60 iken, 1995 de \% 85 olduğu sonucuna ulaşılmıştır.

2009 programının 1995 programı ile bazı amaçları ve içerikleri ortak olmasına karşın, konuları işleyiş̧ yönünden farklılıklar bulunmaktadır. Bu farklılıklara baktı̆̆ımızda; 1995 programında dört ünite bulunmaktadır. $\mathrm{Bu}$ ünitelerin program içerisindeki dağılımına baktığımızda, Atatürkçülük ve Türk Kültürü konularına geniş yer verildiği sonucuna ulaşılmıştır. Bunun yanı sıra, 1995 programında Atatürkçülük ve Türk Kültürü konularının ele alındığı ünitelerden, Toplumsal Yapı ünitesinin program içerisindeki oranı, 2009 programında azaltıldığı sonucuna ulaşılmıştır. 
Sonuç olarak, 1924-1935-1957 ve 1995 programlarına kadar öğrenci merkezli bir eğitim sisteminin benimsenmediği ve öğrencinin daha çok bilişsel alanına ağırlık verildiğini görmekteyiz. Buda öğretmen ve öğrenci arasında tek yönlü bir iletişimin oluşmasına ve öğrencinin süreç içerisinde bilgiyi aktif bir şekilde yapılandırmasına engel olmaktadır. Bu anlayış, 2009 programları ile ortadan kaldırılmaya çalışılmıştır. Çünkü 2009 sosyoloji programı yapılandırmacı eğitim anlayışı benimsemiş ve her öğrencinin öğrenme yollarının ve zekâlarının aynı olmadığı düşüncesinden yola çıkmıştır. Böylelikle 2009 sosyoloji öğretim programı; kazanımları, içeriği, öğrenme-öğretme durumunu ve değerlendirme boyutlarını öğrenci merkezli anlayışa uygun olarak yeniden yapılandırmıştır.

Sosyoloji dersi programında yer alan Atatürkçülük ve Türk Kültürü konusuna yönelik özel amaçlar için hazırlanan etkinliklerin ne kadarının öğrenci seviyesine uygun olduğu araştırılabilir.

Örtük program yolu ile Atatürkçülük ve Türk Kültürü konularının ders kitaplarında öğrencilere nasıl kavratılmaya çalışıldığına yönelik araştırmalar yapılabilir. 


\section{Kaynakça/References}

Arslanoğlu, İ. (2001). Ortaöğretimde sosyoloji ders kitapları. Kastamonu Eğitim Dergisi, 9(1), 67-80.

Aslantürk, Z. ve Amman. M. T. (1992). Sosyolojiye giriş. Bolu: Çamlıca Yayınları.

Başaran, İ.E. ( 2006). Türk eğitim sistemi ve okul yönetimi. İstanbul: Ekinoks Eğitim Danışmanlık Hizmeti ve Basım Yayın Dağıtım.

Başgöz, İ. (1995). Türkiye'nin eğitim çıkmazı ve Atatürk: Sorunlar-Çözüm Aramalart-Uygulamalar. Ankara: Kültür Bakanlığı.

Beydoğan, H. Ö. (1988). Lise sosyoloji müfredat programının değerlendirilmesi. (Yayımlanmamış yüksek lisans tezi). Gazi Üniversitesi, Ankara.

Bursalığlu, Z. (1992). Okul yönetiminde yeni yapı ve davranış. Ankara: Pegem A Yayıncılık.

Cicioğlu H. (1985). Türkiye Cumhuriyetinde ilk ve ortaöğretim. Ankara: Ankara Üniversitesi Basımevi.

Çağlayan, A. (2004). Ĕgitimde özlenen öğretmenler. İstanbul: Ağaç Yayıncılık.

Çimen, L. (1997). 1923'den Günümüze lise sosyoloji ders kitaplarl ve sosyalleştirme rolleri. (Yayınlanmamış yüksek lisans tezi). Marmara Üniversitesi, İstanbul.

Demirel, Ö. (2010 ). Eğitimde program geliştirme. Ankara: Pegem A Yayıncılık.

Erdem, S. (2003). Sosyoloji. İstanbul: Fil Yayın Evi.

Erden, M. (1998) . Ĕgitimde program değerlendirme. Ankara: Anı Yayıncılık.

Ergun, D. (1979). 100 sorudan sosyoloji el kitabı. İstanbul: Gerçek Yayınevi.

Güleryüz, H. (2000). Eğitim programlarının dili ve yaratıcı ögrenme. Ankara: Pegem A Yayıncılık.

Güngör, E. (1982). Dünden Bugünden Tarih, Kültür, Milliyetçilik. Ankara: Mayaş Yayınları.

Kaplan, İ. (2002). Türkiye'de milli eğitim ideolojisi. İstanbul: İletişi Yayınları.

Karakaya, Ş. (2004). Eğitimde program geliştirme çalışmaları ve yönelimler. Ankara: Asil Yayın Dağıtım.

Kurtkan, A.(1980). Sosyoloji. İstanbul: Milli Eğitim Basımevi

MEB, (1952). Lise müfredat programı. Ankara: Milli Eğitim Basımevi.

MEB (1970). Lise müfredat programı. Ankara: Milli Eğitim Basımevi.

MEB (1973). Lise müfredat programı. Ankara: Milli Eğitim Basımevi.

MEB (2009). Ortaöğretim sosyoloji dersi öğretim programı. Ankara: Milli Eğitim Bakanlığı Yayınları.

Mengüssoğlu, T.(1975). Lise müfredat programı hakkında düşünceler. İstanbul: Remzi Kitapevi.

Meriç, C.(1974). Bu Ülke. İstanbul: Ötüken Yayınları.

Meriç, C.(2002). Jurnal 2. İstanbul: İletişim Yayınları.

Merter, F. ve Yıldız, H.(2010). Cumhuriyetten günümüze lise programlarının Atatürk İlke ve İnkılâplarını genç nesillere benimsetmesi bakımından değerlendirilmesi. Mehmet Akif Ersoy Üniversitesi Eğitim Fakültesi Dergisi, 10(20), 1-27.

"Mukaddime" İ̧̧timaiyat Mecmuası, 1917, Y1l 1, Sayı:1, S. 2.

Tan, M. (1987). Ortaöğretim kurumlarında sosyoloji öğretimi. Ortä̈ğretim kurumlarında sosyal bilimler ögretimi ve sorunları. Ankara: TED Yayınları.

T.C. Kültür Bakanlığı (1938). Lise programı. İstanbul: Devlet Basımevi

T.C. Maarif Vekâleti (1956). Lise programı. Ankara: Maarif Basımevi. 
T.C. Maarif Vekâleti (1960). Lise programı. Ankara: Maarif Basımevi.

Tebliğler Dergisi, Cilt 4, Sayı 138, Y1l 1941.

Tebliğler Dergisi, Cilt 10, Sayı 450, Y11 1947.

Tebliğler Dergisi, Cilt, 17, Sayı, 816, Y11 1954.

Tebliğler Dergisi, Cilt, 20, Sayı, 976, Y11 1957.

Tebliğler Dergisi, Cilt, 22, Say1, 1086, Y11 1959.

Tebliğler Dergisi, Cilt 23, Say1 1117, Y1l 1960.

Tebliğler Dergisi, Cilt 23, Sayı 1119, Y1l 1960.

Tebliğler Dergisi, Cilt 24, Sayı 1174, Y1l 1961.

Tebliğler Dergisi, Cilt 97, Sayı, 1900, Y11, 1976

Tebliğler Dergisi, Cilt 43, Sayı, 2062, Y11, 1980.

Tebliğler Dergisi, Cilt 41, Say1, 2104, Y11, 1981.

Tebliğler Dergisi, Cilt 56, Sayı, 2444, Y11, 1995

Tebliğler Dergisi, Cilt 56, Sayı, 2444, Y11, 1995

Tebliğler Dergisi, Cilt 34, Sayı, 2488, Y11, 1998

Tebliğler Dergisi, Cilt 78, Say1, 2104, Y11, 2007

Tebliğler Dergisi, Cilt 73, Sayı, 2635, Y11, 2009.

Tebliğler Dergisi, Cilt73, Say1, 2629, Y11, 2010.

Sadak, N. (1939). Sosyoloji. İstanbul: Maarif Matbaası.

Ülken, H. Z. (1966). Dünya ve Türkiye'de sosyoloji öğretimi ve araştırmaları. İstanbul: Türk Sosyoloji Cemiyeti Yayınlar1.

Uçan, A. (1989). Çağdaş eğitimde program geliştirme sürecine genel bir bakış. Ĕ̆itim Bilimleri Sempozyumu. İnönü Üniversitesi Eğitim Fakültesi, 15 - 17 Mayıs 1989, Malatya.

Yazar, T. (2001). Lise sosyoloji öğretim programının değerlendirilmesi. (Yayımlanmamış yüksek lisans tezi). Anadolu Üniversitesi Eğitim Bilimler Enstitüsü, Eskişehir.

Yıldırım, A. ve Şimşek, H. (2006). Sosyal bilimlerde nitel araştırma yöntemleri. Ankara: Seçkin Yayıncılık.

Yücel, H.A.(1938). Türkiye’de ortaöğretim. İstanbul: Devlet Basımevi.

Zabun, B. (2002). Türkiye'de ortaöğretimde sosyoloji öğretimi. (Yayınlanmamış yüksek lisans tezi). Gazi Üniversitesi Eğitim Bilimler Enstitüsü, Ankara.

1340 (1924) Tarihli orta mektep ve lise müfredat programlarına zeyl. İstanbul: Devlet Matbaas1. 